\title{
Continuous Manufacturing of High Quality Pharmaceutical Cocrystals Integrated with Process Analytical Tools for In-Line Process Control
}

\author{
Hiren G. Moradiya, ${ }^{\dagger}$ Muhammad T. Islam, $^{\dagger}$ Nikolaos Scoutaris, ${ }^{\dagger}$ Sheelagh A. Halsey, ${ }^{\ddagger}$ \\ Babur Z. Chowdhry, ${ }^{\dagger}$ and Dennis Douroumis* ${ }^{\dagger}$ \\ ${ }^{\dagger}$ Faculty of Engineering and Science, University of Greenwich, Medway Campus, Chatham Maritime, Kent ME4 4TB, U.K. \\ ${ }^{\ddagger}$ ThermoFisher Scientific, Stafford House, Boundary Way, Hemel Hempstead HP2 7GE, U.K.
}

Supporting Information

\begin{abstract}
A continuous manufacturing process for pharmaceutical indomethacin-saccharine cocrystals was achieved by extrusion processing with high throughput. Down-stream milling and blending of the extrudates was followed by feeding the formulated cocrystals in a capsule-filling machine. By applying a quality by design approach, the process was optimized and scaled up to produce 3000 capsules/h of pharmaceutical cocrystals. Process analytical tools such as near infrared reflectance and spatial filter velocimetry probes were coupled at various process stages for in-line monitoring and quality control. Further physicochemical characterization of extruded batches confirmed the manufacturing of high quality cocrystals. A fully integrated continuous process starting from raw materials to produce a finished product was assembled with only six unit operations and a small footprint. The study is a paradigm of continuous manufacturing of pharmaceutical cocrystals.
\end{abstract}

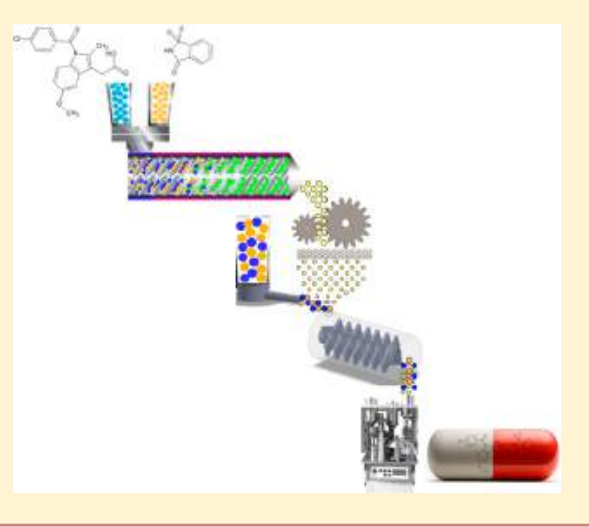

\section{INTRODUCTION}

Pharmaceutical industries are facing enormous challenges in their quest to satisfy regulatory constraints, flexible market demands, operational complexities, and economic limitations. ${ }^{1-4}$ Market globalization has considerably decreased the patent lifetime of new-finished drug products. This has forced manufacturers to minimize the development time associated with new drugs as well as maximize their throughput. To date most pharmaceutical processes involve conventional manufacturing approaches, such as batch production. However, batch based manufacturing presents several disadvantages such as defined batch size, multiple sequential steps, interruptions, long waiting and throughput times, raw material waste, extensive validation, and scale up activities compared to continuous processes. ${ }^{1}$ Because of the foregoing market needs and drawbacks associated with batch manufacturing, regulatory bodies are encouraging the development and implementation of innovative pharmaceutical processes such as continuous manufacturing. Continuous manufacturing $(\mathrm{CM})$ is well accepted in other industries such as food, paper, plastic, and ceramic, while it is now being gradually accepted in the pharmaceutical industry. Among the several advantages of CM is the increased efficiency of equipment use, savings in energy consumption, reduction of scrap/waste, lower costs, safety, and less complex scale-up, but-most importantly-fully automated finished product manufacturing and the reduced time to market (throughput manufacturing time). One of the biggest challenges facing the pharmaceutical industry in moving forward is to identify model CM platforms and, consequently, deal with the "how" or technical issues involved in their implementation. Various approaches have been reported for continuous manufacturing such as roller compaction and twin-screw granulation, ${ }^{5,6}$ but only a few have resulted in complete multiunit processes. ${ }^{7-9}$ A complete end-to-end process which involves synthesis, purification, and formulation of a final dosage form has been reported by Mascia et al. for the manufacturing of aliskiren hemifumarate tablets. Pharmaceutical cocrystals have attracted significant interest in the past few years due to their potential to modify the physicochemical properties of a drug substance such as stability, solubility, and bioavailability. The development of a new solid form of a drug substance by altering the crystal packing through drug-conformer supramolecular interactions has led to the formation of various cocrystals products. ${ }^{10-14}$ Herein, we introduce a secondary continuous cocrystallization manufacturing process by means of hot melt extrusion (HME) with in-line integrated process analytical tools for process monitoring and quality control. Although HME has been previously used for the formation of pharmaceutical cocrystals, ${ }^{15-20}$ this is the first report of a fully scalable, continuous HME process coupled with PAT probes ${ }^{21}$ resulting in a final dosage form.

\section{MATERIALS AND METHODS}

Materials. Indomethacin ( $\gamma$-form, IND, >98.0\%) and saccharin ( $\mathrm{SCH},>99.0 \%$ ) were purchased from Tokyo Chemicals (Tokyo, Japan) and Sigma-Aldrich Company Ltd. (Dorset, UK), respectively, and used

Received: March 13, 2016

Revised: April 27, 2016

Published: April 28, 2016 
as received. All solvent used for HPLC analysis were of analytical grade (Fisher Chemical, UK).

Description of Continuous Processing. Equimolar amounts (1:1) of IND and SCH were accurately weighed and homogeneously blended for 10 min using a Turbula mixer. The prepared blended powder was fed into a twin-screw extruder (Eurolab 16, Thermo Fisher, Germany) via a DD Flexwall 18 feeder (Brabender Technology, Germany). Table 1 shows the settings for the processing parameters

Table 1. Processing Parameter Settings Applied for the Development and Scale-up of IND-SCH Cocrystals Using a Constant Degree-of-Fill ${ }^{a}$

\begin{tabular}{|c|c|c|c|c|c|}
\hline & $\begin{array}{l}\text { temperature profile }\left({ }^{\circ} \mathrm{C}\right) \\
\text { (feeder } \rightarrow \text { die })\end{array}$ & $\begin{array}{l}\text { screw rate } \\
\text { (rpm) }\end{array}$ & $\begin{array}{l}\text { feeder rate } \\
(\mathrm{kg} / \mathrm{h})\end{array}$ & $\begin{array}{l}\text { residence } \\
\text { time }(s)\end{array}$ & cocrystal \\
\hline F1 & $\begin{array}{c}50-70-95-130-140- \\
140-145-145-145\end{array}$ & 10 & 0.10 & 230.0 & $\mathrm{X}$ \\
\hline F2 & $\begin{array}{c}70-95-145-150-155- \\
155-155-155-155\end{array}$ & 10 & 0.10 & 230.0 & $\sqrt{ }$ \\
\hline F3 & $\begin{array}{c}70-95-145-150-155- \\
155-155-155-155\end{array}$ & 30 & 0.30 & 176.5 & $\mathrm{X}$ \\
\hline F4 & $\begin{array}{c}50-70-95-155-160- \\
165-165-165-165\end{array}$ & 30 & 0.30 & 176.5 & $\sqrt{ }$ \\
\hline F5 & $\begin{array}{c}50-70-95-155-160- \\
165-165-165-165\end{array}$ & 100 & 1.0 & 45.7 & $\mathrm{X}$ \\
\hline F6 & $\begin{array}{c}70-95-155-165-175- \\
175-175-175-175\end{array}$ & 75 & 1.0 & 85.4 & $\sqrt{ }$ \\
\hline F7 & $\begin{array}{c}70-95-155-165-175- \\
175-175-175-175\end{array}$ & 100 & 1.0 & 85.4 & $\sqrt{ }$ \\
\hline F8 & $\begin{array}{c}70-95-155-165-175- \\
175-175-175-175\end{array}$ & 100 & 1.5 & 45.7 & $\sqrt{ }$ \\
\hline
\end{tabular}

such as the temperature profiles, screw speed, and feed rate used for the optimization of the synthesis of the cocrystals via HME. The twin-screw extruder was operated without a die, and the extruded cocrystals were collected in powder form.

The as-synthesized cocrystals were fed into a cutter mill (Cutting Mill SM 100, Retsch, UK) for further particle size reduction using a constant rotating speed of $1500 \mathrm{rpm}$. For the purposes of the size reduction, a $250 \mu \mathrm{M}$ sieve was placed at the bottom of the casing holds of the cutter mill in order to process the cocrystals discharged at the end of the extrusion process. A convective twin-screw blender was also placed underneath the cutter mill in order to process the micronized cocrystals.

The role of the blender was to provide continuous, homogeneous, and uniform powder blending. The powder flow was axial by varying the impeller rotation ( 34 blades), while the processing angle was kept constant $\left(0^{\circ}\right.$ angle). A second gravimetric feeder (K-tron T35, Coperion, Stockport, UK) was calibrated to supply the bulking excipients at various feed rates during process optimization and scale-up $(0.3-3.75 \mathrm{~kg} / \mathrm{h})$. The blended powders were fed directly from the outlet of the conveyor into the hopper of the Mini-Cap capsule filler (Karnavati Engineering Ltd., India).

Off-Line Physicochemical Characterization. Differential scanning calorimetry (DSC) analysis was carried out by using a MettlerToledo 823e instrument (Greifensee, Switzerland). The accurately weighed samples were crimped in $40 \mu \mathrm{m}$ aluminum pans and heated from 25 to $250{ }^{\circ} \mathrm{C}$ at a scan rate of $10^{\circ} \mathrm{C} / \mathrm{min}$ using nitrogen as a purge gas at a flow rate of $50 \mathrm{~mL} / \mathrm{min}$. STARe excellence software provided with the instrument software was used for further data analysis.

$\mathrm{X}$-ray powder diffraction (XRPD) was used to determine the solid state of bulk materials, physical mixtures, and hot-melt extrudates using a Bruker D8 Advance (Germany) instrument in theta-theta mode. A Cu anode at $40 \mathrm{kV}$ and $40 \mathrm{Ma}$, parallel beam Goebel mirror, $0.2 \mathrm{~mm}$ exit slit, LynxEye Position Sensitive detector with $3^{\circ}$ opening (LynxIris at $6.5 \mathrm{~mm}$ ) and sample rotation of $15 \mathrm{rpm}$ were used. Each sample was scanned from 2 to $40^{\circ} 2 \theta$ with a step size of $0.02^{\circ} 2 \theta$ and a counting time of $0.3 \mathrm{~s}$ per step. Rietveld refinements were performed using TOPAS V4.2 (Bruker), and crystal structures were retrieved from the Cambridge Structural Database.
The morphology of bulk IND, SCH, and the extruded cocrystals was examined by scanning electron microscopy (Hitachi SU8030, Japan). Samples were placed on a thin layer of Mikrostik nonconductive adhesive (Agar scientific, UK) on an aluminum stub and coated with chromium under an atmosphere of argon at room temperature. Scanning electron microscopy (SEM) images were obtained by using an electron beam accelerating voltage of $2 \mathrm{kV}$.

Dissolution studies were conducted by using a USP II paddle apparatus (Varian 705, US). The amount of extruded powders was equivalent to $25 \mathrm{mg}$ of IND, placed into $900 \mathrm{~mL}$ of phosphate buffer solution ( $\mathrm{pH} 6.8)$, in each dissolution vessel $(n=3)$. The temperature of the dissolution media was maintained at $37^{\circ} \mathrm{C}$ with a paddle rotation of $100 \mathrm{rpm}$. Samples, about $2-3 \mathrm{~mL}$, were withdrawn at $15,30,60$, and $120 \mathrm{~min}$ intervals and filtered with a $200 \mu \mathrm{m}$ filter prior to HPLC analysis.

The content of IND in all the samples was confirmed by HPLC. The experiments were performed on an HPLC system (Agilent Technologies, 1200 series) equipped with a quaternary pump. A Hichrom S50DS2-4889 $(5 \mu \mathrm{m} \times 150 \mathrm{~mm} \times 4 \mathrm{~mm})$ column was employed. Column temperature and retention time were set at $25{ }^{\circ} \mathrm{C}$ and $4 \mathrm{~min}$, respectively. The mobile phase used was 70:30:0.2 (v/v/v) methanol/water/acetic acid. The sample volume was $20 \mu \mathrm{L}$, injected by using an auto sampler, the flow rate used was $1.5 \mathrm{~mL} / \mathrm{min}$, and the detector was set at a wavelength of $260 \mathrm{~nm}$. The calibration curve for IND was plotted over a concentration range of $10-50 \mu \mathrm{g} / \mathrm{mL}$.

Off-line particle size analysis of the extruded cocrystals was conducted by using a dry powder dispersion unit (Scirocco 2000) of a Mastersizer 2000 (Malvern, Worcestershire, UK) laser diffraction particle size analyzer. Postextruded samples were placed in a vibratory tray, which continuously controls the rate of powder flow, in order to measure the particle size off-line. Three particle size measurements were obtained, in continuous sequence, in order to assess the reproducibility of each batch of extrudates. The Mastersizer 2000 software automatically displayed particle size distributions.

Fourier transform infrared (FT-IR) spectra were obtained using a PerkinElmer spectrophotometer (Spectrum 100, PerkinElmer, US) equipped with a crystal diamond universal ATR sampling accessory (UATR). Solid samples were placed in contact with the universal diamond ATR top-plate and an average spectrum of 64 scans was recorded in the $4000-400 \mathrm{~cm}^{-1}$ wavenumber range.

In-Line Process Monitoring. Diffusion reflectance near infrared (NIR) spectra were continuously collected in-line and noninvasively during extrusion cocrystallization using Fourier-Transform Antaris MX NIR analysers (Thermo Fisher Scientific, United Kingdom) supplied with an InGAs detector, a quartz halogen lamp, and a fiber optic probe placed at the end of the extruder. Spectra were recorded every $1 \mathrm{~min}$ in the $10000-4000 \mathrm{~cm}^{-1}$ wavenumber region with a resolution of $16 \mathrm{~cm}^{-1}$ and averaged over 64 scans. A transmission probe was fitted at the end of the extruder, and the reflectance probe was inserted in the first mixing zone of the extruder barrel.

In-line particle size measurements were carried out by using a Parsum probe (Parsum IPP70; Malvern, UK). Two particle size probes were used, and the operational inlet and external pressures were set at 15 and $2 \mathrm{~L} / \mathrm{min}$, respectively. The first probe was directly placed at the end of the extruder and the second was placed underneath the 250 mesh of the cutter mill to measure the as-made and micronized cocrystals, respectively. The particle size data were collected by using the IPP software provided with the instrument. The scan rates used were $2-2.5 \mathrm{~m} / \mathrm{s}(0.250 \mathrm{MHz}$, free fall), $10-30 \mathrm{~m} / \mathrm{s}(5 \mathrm{MHz}, \mathrm{D} 23$ in-line disperser). For the process optimization, the D23 disperser attachments or the "free fall" mode were used.

The probes are operated by compressed air to create a constant curtain of scavenging air in front of the measurement optical system and for the carriage and thinning of the particle jet. The compressed air required is fed from an air regulation kit to the measurement chamber inside the sensors and from there to the accessories (Figure S4). The Parsum probe is based on the principle of spatial filter velocimetry, and thus the size and velocity can be simultaneously extracted from particles as they pass through a laser beam, casting shadows onto a linear array of optical fibers. 
Residence Time Distribution (RTD). Residence time distribution was measured by using a modified approach similar to Ziegler et al. (2002) corresponding to turning off the supply of an inert tracer. The RTD is usually presented as the exit age distribution $E(t)$ of a material leaving the extruder. It is estimated as the response at the die outlet to pulse tracer at $t=0$ in some part of the extrusion barrel. In this case the inert tracer was sodium fluorescein-FINa (Sigma-Aldrich, UK). This is commonly referred to as a washout experiment (Nauman, 1985), and for accurate determinations of residence time, the tracer should not affect the properties of the material being processed. Samples were collected at the discharge end of the extruder at $10 \mathrm{~s}$ time intervals, and the concentration of tracer was measured using a Varian Cary 300 UV-Vis spectrometer (Canada). The collected samples $(5 \mathrm{mg})$ were dissolved in distilled water, and the concentration of FINa was measured at $475 \mathrm{~nm}$. Prior to the estimation of FlNa concentration, calibration curves were plotted from $2-25 \mu \mathrm{g} / \mathrm{mL}$.

\section{RESULTS AND DISCUSSION}

Figure 1 illustrates a schematic diagram of the HME process for the formation of IND-SCH cocrystals with the capability to

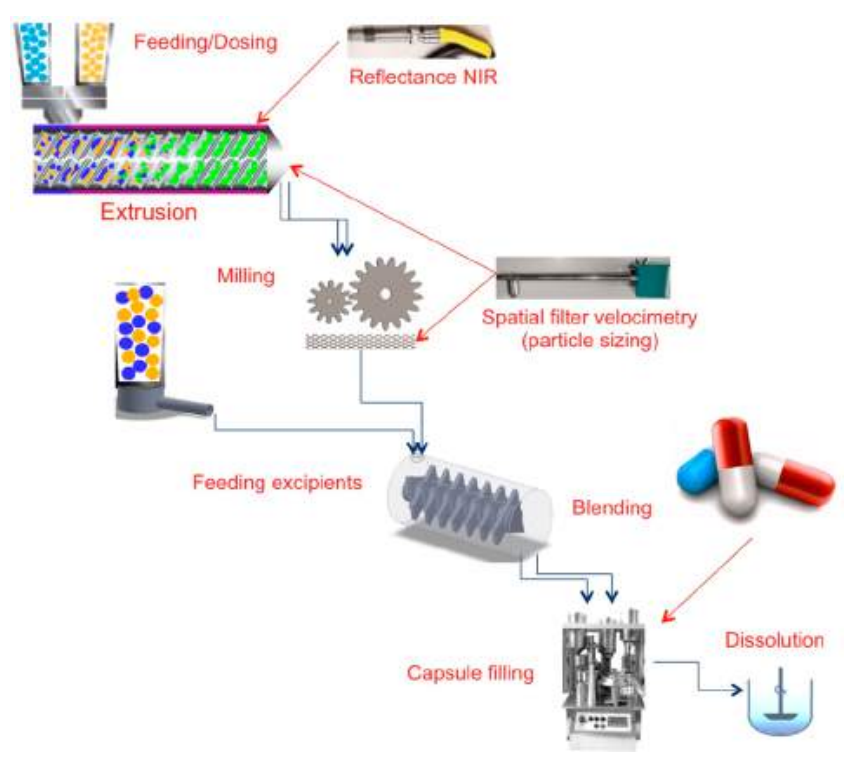

Figure 1. Schematic diagram of CM processing by using a twin-screw extruder, PAT tools, and downstream equipment for the formation of pharmaceutical cocrystals.

operate for several days and produce 60000 capsules/h processed by using a $16 \mathrm{~mm}$ twin-screw extruder. The system comprises only six unit operations with a footprint of $0.8 \times 3.5 \mathrm{~m}^{2}$. The diagram also shows the PAT tools coupled at critical process steps consisting of one NIR reflectance probe and two partial filter velocimetry particle size probes.

The formation and quality optimization of IND-SCH cocrystals was conducted in the absence of an extrusion die, and the extrudates were collected in dry powder form. Studies revealed that the temperature profile, feed rate, and screw speed were the three critical process parameters (CPP) required for the engineering of high quality cocrystals. Screw configuration is another key parameter, ${ }^{22}$ but on this occasion we used a standard screw configuration provided by the instrument manufacturer. Table 1 depicts the experimental plan that was designed in order to identify the space control and process boundary for high quality cocrystal manufacturing. The rationale of the experimental set in Table 1 was to conduct scale-up of the formed corystals by increasing initially the feed rate of the drug/conformer and subsequently the screw speed and barrel temperature if necessary. As shown, complete cocrystal formation was not achieved when the initial extrusion temperature was set at $145^{\circ} \mathrm{C}$ with a screw speed of $10 \mathrm{rpm}$, as small traces of unreacted material were detected by using DSC and XRPD analysis (Supporting Information). Batches extruded at $155^{\circ} \mathrm{C}$, which is the eutectic temperature of the IND-SCH physical blend, ${ }^{23}$ showed cocrystal formation and the absence of unreacted starting materials. The effect of screw speed and feed rate was further investigated by increasing the rates to $30 \mathrm{rpm}$ and $0.3 \mathrm{~kg} / \mathrm{h}$, respectively, for the same temperature profile. Higher screw speeds facilitate the rapid transport of material through the extrusion barrels of the hot-melt extruder with less residence time and this parameter is directly related to the feeding rate. ${ }^{24}$ However, higher feeding rates (at constant screw speed) can cause material blockage in the extruder. An increase in the screw/feed rates resulted, again, in incomplete cocrystal formation and the presence of unreacted materials at maximum barrel temperatures of $155^{\circ} \mathrm{C}$. Manufacturing of IND-SCH cocrystals at $30 \mathrm{rpm}$ screw speed required a further increase in extrusion temperature $\left(165^{\circ} \mathrm{C}\right)$. Dhumal et al. (2010) reported that temperatures higher than the eutectic point lead to material melting and facilitated mass transfer due to additional degrees of freedom with enhanced molecular collisions. Nevertheless, the obtained throughput of $0.3 \mathrm{~kg} / \mathrm{h}$ is considered low for a typical HME plant, and thus process scale-up was optimized with a target of $1.0-1.5 \mathrm{~kg} / \mathrm{h}$. The screw speed was increased proportionally to the feed rate in order to achieve a constant degree-of-fill for the fed drug and coformer. It is obvious that when changes in extrusion screw speed and the feed rate are made, the temperature profile has to be optimized when using an extruder of the same size. This is an interesting development, as volumetric scale-up in plastic or polymer processing can usually be achieved by altering only one process parameter at a time. ${ }^{25}$ The use of the high extrusion temperatures, above the drugcoformer eutectic melting point, increases the possibility of drug degradation and also limits the formation of cocrystals. However, extrusion at $175^{\circ} \mathrm{C}$ did not affect IND and enabled the formation of cocrystals. In addition, the residence time for extrusion was significantly reduced from $230 \mathrm{~s}$ to $45.7 \mathrm{~s}$ without having an effect on the resulting product quality. Figure 2 provides a schematic representation of the process boundary and the melt temperature dependence. As can be seen $175^{\circ} \mathrm{C}$ is a critical processing temperature as cocrystals are formed at feed: screw speed rates of $1.0 \mathrm{~kg} / \mathrm{h}: 75 \mathrm{rpm}$ and $1.5 \mathrm{~kg} / \mathrm{h}: 100 \mathrm{rpm}$, respectively.

The RTD is a key tool with which to characterize the extrusion cocrystallization process and it is affected by the screw design/ configuration and operating conditions. ${ }^{26,27}$ The RTD is usually presented as the exit age distribution $E(t)$ of a material leaving the extruder. It is estimated as the response at the die outlet to pulse tracer at $t=0$ in some part of the extrusion barrel. The inset in Figure 2 shows the RTD of the scaled-up batches $\left(170{ }^{\circ} \mathrm{C} /\right.$ $100 \mathrm{rpm}$ ) derived by using the following equations:

$$
\begin{aligned}
& E(t)=\frac{C(t)}{\sum C(t) \Delta t} \\
& t=\frac{\sum t C(t) \Delta t}{\sum C(t) \Delta t}
\end{aligned}
$$

where $C(t)$ is the tracer concentration, $\Delta t$ is the sampling period, and $t$ is the sampling time.

The RTD was found to be $46.7 \mathrm{~s}$ with a time delay of $20 \mathrm{~s}$ and then an increase to reach a maximum within $40-50 \mathrm{~s}$ followed by 


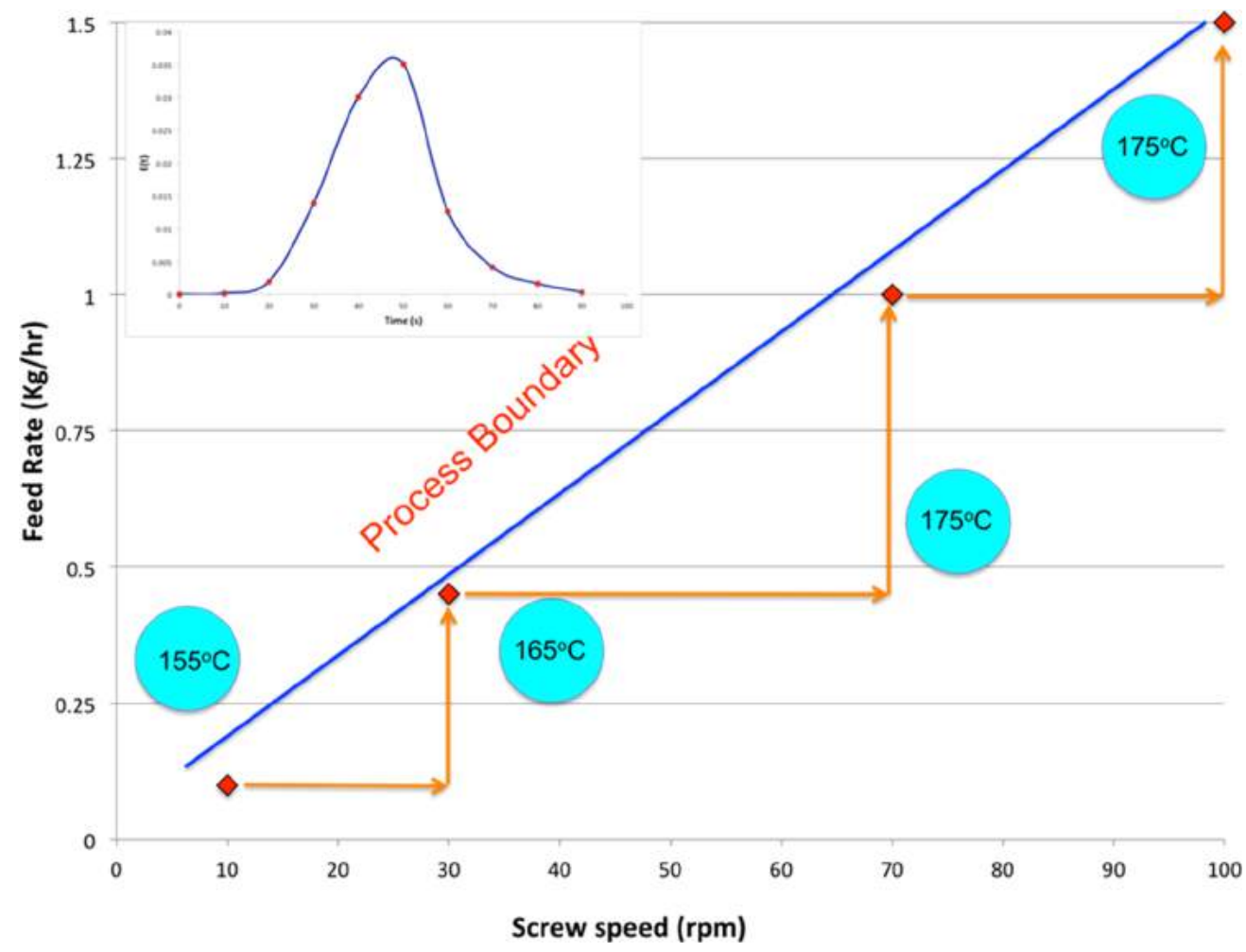

Figure 2. Schematic diagram of process boundary and scale-up (inset: RTD curve of scaled-up CM of IND-SCH cocrystals $100 \mathrm{rpm} / 175^{\circ} \mathrm{C}(1.5 \mathrm{~kg} / \mathrm{h})$.

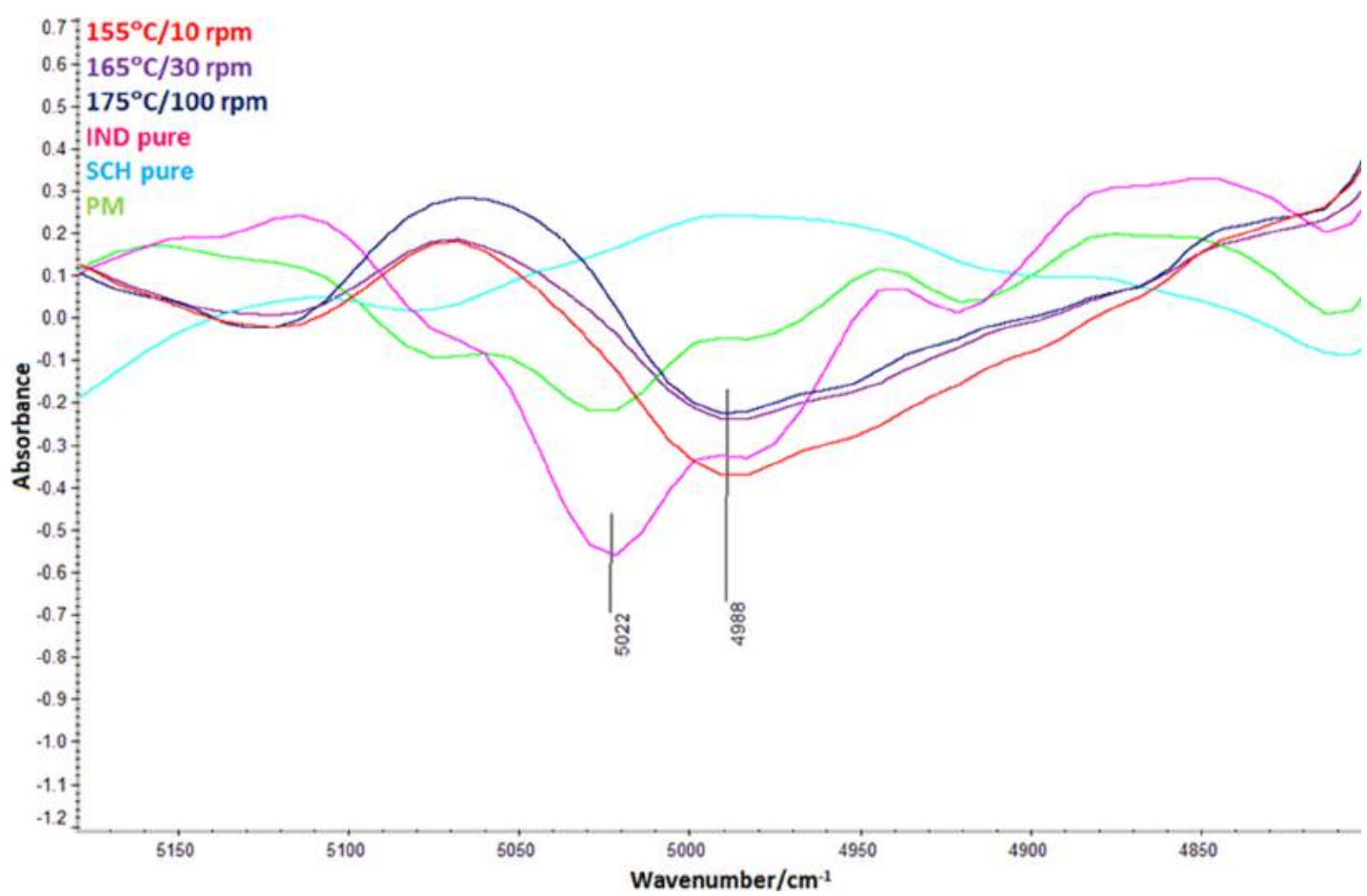

Figure 3. NIR second derivative reflectance spectra of bulk IND, SCH, PM, and in-line spectra of IND-SCH extruded cocrystals at various screw speed/temperature configurations collected from the extrusion processing.

a relative rapid decrease. ${ }^{28,29}$ As expected, RTD reduced with an increase in the screw speed.

The second goal of the study was to align the operation units with HME for the production of gelatin capsules filled with IND-SCH cocrystals. As Figure 1 shows, the extruded cocrystals are fed into a cutter mill to reduce the particle size (downstream equipment) and collected in a convective blender following blending with other excipients from a second gravimetric feeder ${ }^{30}$ calibrated and set at $0.45 \mathrm{~kg} / \mathrm{h}$. The blend of cocrystals and excipients are subsequently fed into the hopper of an automated capsule-filling machine to produce hard gelatin capsules (size 4) where each capsule contained the equivalent of $25 \mathrm{mg}$ of IND. The milled cocrystals were blended with lactose, MCC, and $\mathrm{SiO}_{2}$ at 40.0:31.5:28.3:0.2 wt/wt ratios. The blending rate of the 


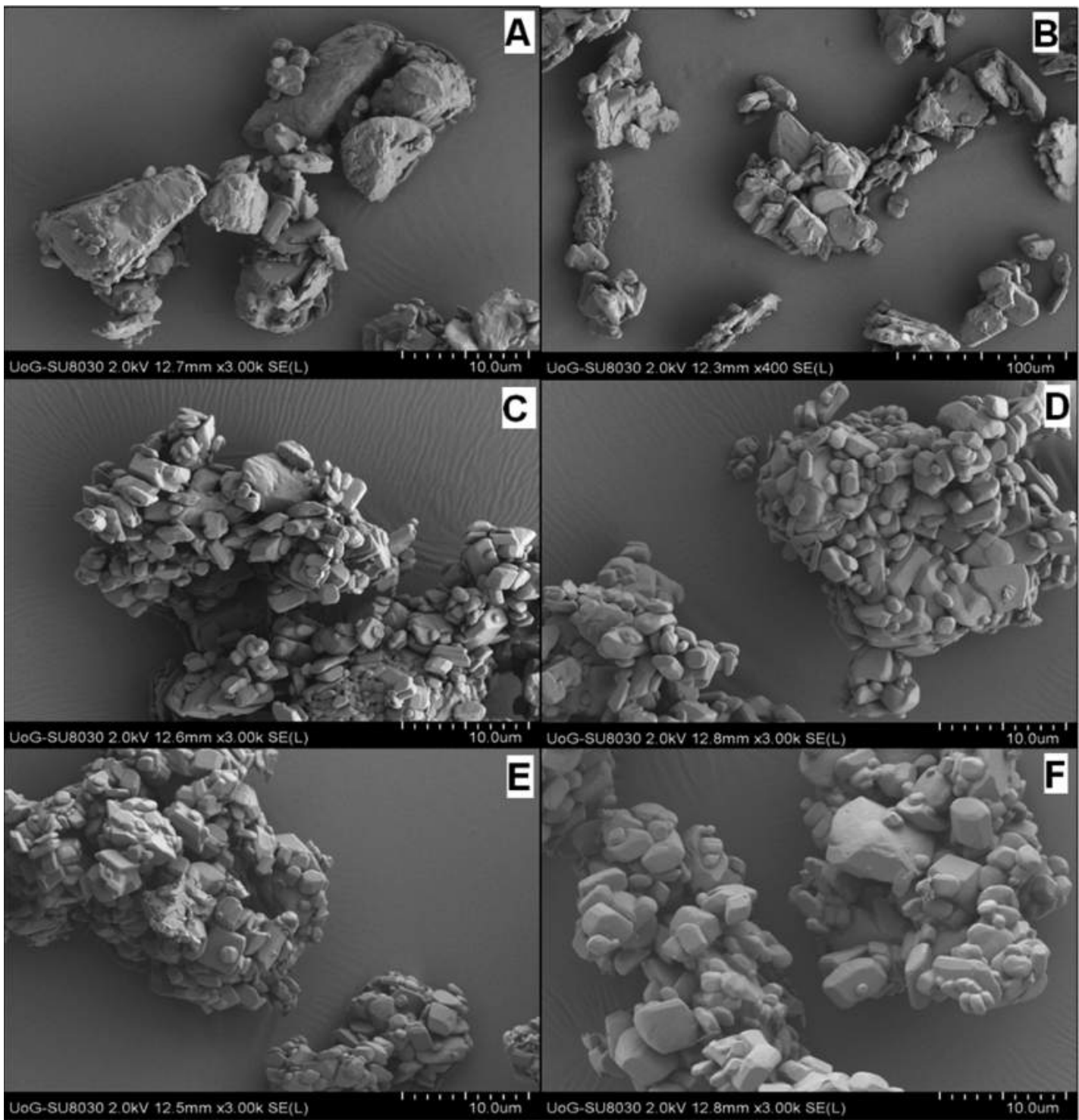

Figure 4. SEM images of HME processed cocrystals of (A) bulk IND, (B) bulk SCH, (C) $10 \mathrm{rpm} / 155^{\circ} \mathrm{C}$, (D) $30 \mathrm{rpm} / 165^{\circ} \mathrm{C}$, (E) $100 \mathrm{rpm} / 175^{\circ} \mathrm{C}$ $(1.0 \mathrm{~kg} / \mathrm{h})$, and $(\mathrm{F}) 100 \mathrm{rpm} / 175^{\circ} \mathrm{C}(1.5 \mathrm{~kg} / \mathrm{h})$.

twin-screw conveyor was set at $0.75 \mathrm{~kg} / \mathrm{h}$, while the capsule filler was programmed to follow a $10 \mathrm{~min}$ lag period prior to capsule filling, in order to allow the transfer of enough material from the conveyor to the capsule machine hopper. The process scale-up allowed the production of IND-SCH capsules at a rate of $3000 / \mathrm{h}$, which was the maximum operating rate of the capsule-filling device. The CM of the extruder and the downstream equipment was allowed to operate successfully for $3 \mathrm{~h}$.

Process monitoring and quality control were achieved by using an in-line NIR probe at the end of the extruder and a particle size probe placed underneath the cutter mill. The NIR probe is set to monitor the "as made" IND-SCH cocrystals, while the spatial velocimetry particle probe is used to continuously measure the size of the micronized particles. The coupling of HME with PAT tools is not limited to these two CM probes; it can involve additional PAT tools such as Raman or ultrasonic probes at different stages of the manufacturing process.

Off-line NIR spectra of IND, SCH, and the physical mixture (PM) were measured to identify the characteristic vibrational bands of these materials so that any new vibrational bands formed during extrusion could be attributed to the cocrystals.
The second derivative NIR spectra of IND, SCH, and the PM in the $4200-6300 \mathrm{~cm}^{-1}$ wavenumber region are shown in Figure 1S. The characteristic vibrational bands of the PM fall between the two component bands, and no shift can be detected, indicating no interaction between the components. As shown in Figure 3 the second derivative spectra of bulk components and the extruded cocrystals show significant differences due to band shifts.

The absorption band at $5022 \mathrm{~cm}^{-1}$ is attributed to the $\mathrm{OH}$ stretching of the IND molecule. In the spectrum of the extruded cocrystals, the band was shifted to $4988 \mathrm{~cm}^{-1}$, and it was attributed to the stretching of $\mathrm{OH}$ groups. ${ }^{31}$ The band shift at lower wavenumber is related to the $\mathrm{H}$-bonding between the $-\mathrm{OH}$ with the $-\mathrm{NH}$ group of $\mathrm{SCH}$ due to the formation of cocrystals between IND and SCH. ${ }^{32,33}$ It can also be seen that the intensity of the band at $4988 \mathrm{~cm}^{-1}$ is identical for the batches processed between 155 and $165{ }^{\circ} \mathrm{C}$, while it gets stronger for those processed at $175{ }^{\circ} \mathrm{C}$. The difference is not associated with the quality of the cocrystals, but to the increase in the screw speed, which has an effect on the NIR recorded spectra. Previous studies showed that the pressure and torque change in the extruder barrel or the die explains the variation in the intensity of the NIR spectra. ${ }^{34}$ 
A)

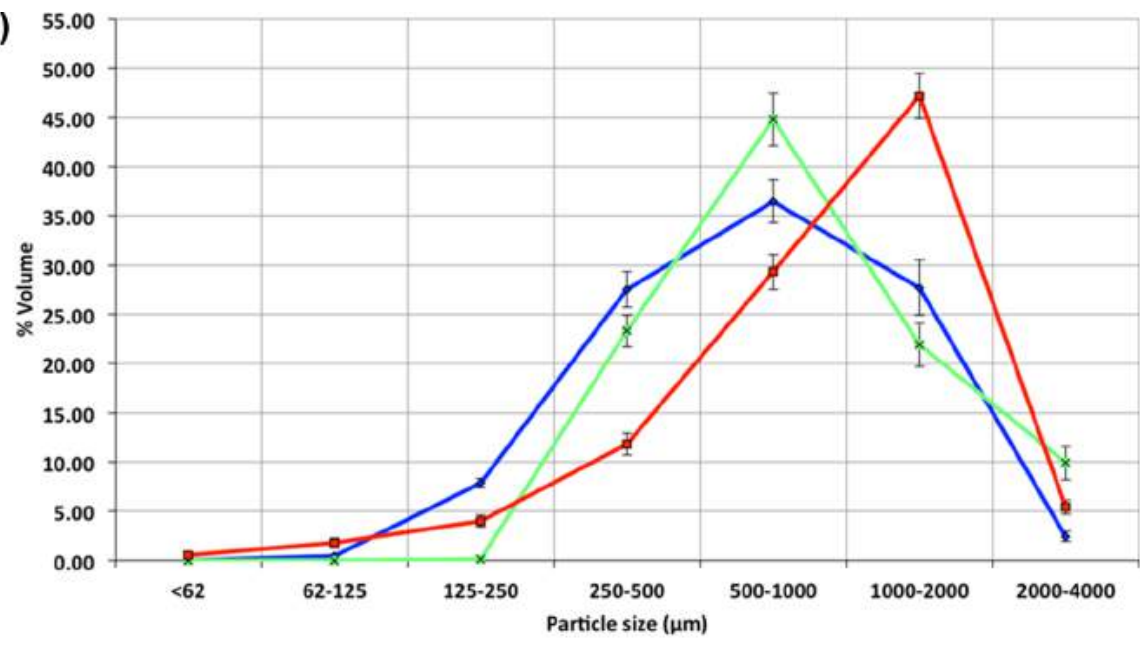

$\rightarrow$ Sieve $\rightarrow$-Free fall $\rightarrow-D 23$ Inline

B)

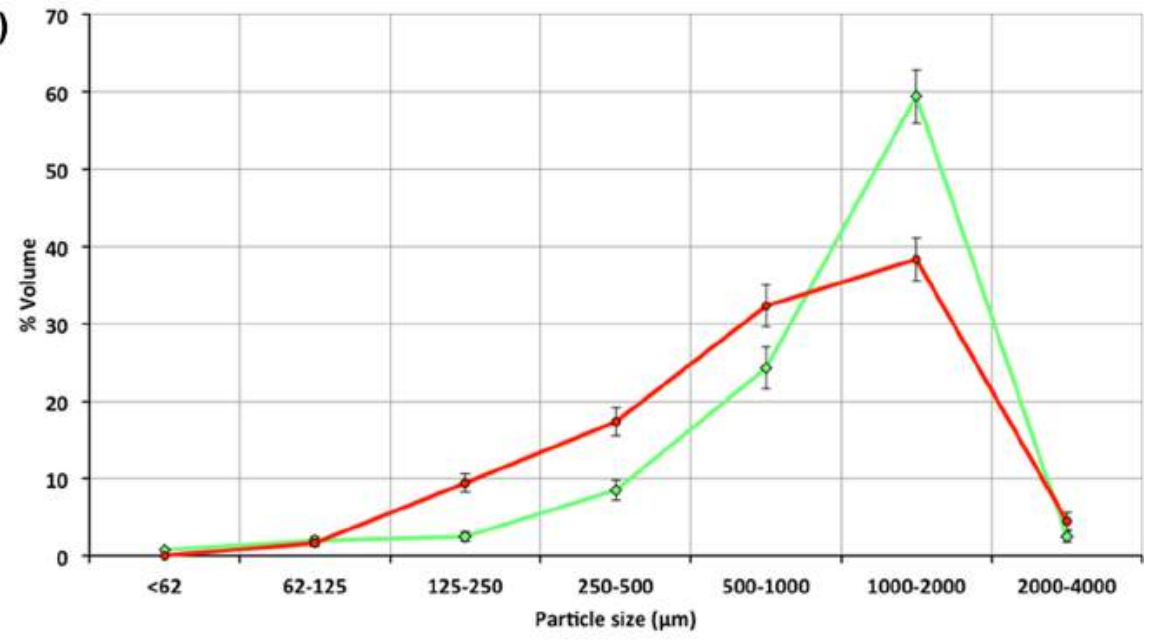

C)

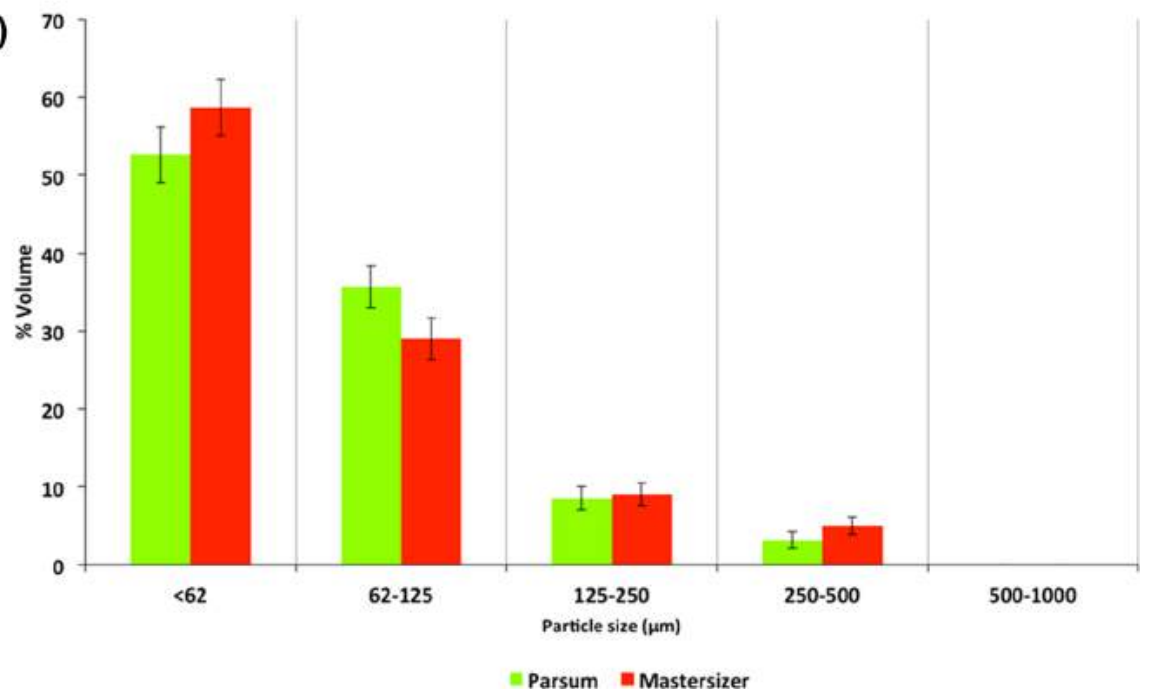

Figure 5. Particle size analysis by using (A) sieve, and Parsum probe (free fall, $\mathrm{D} 23$ inductor) for the $30 \mathrm{rpm} / 165^{\circ} \mathrm{C}$ "as made" cocrystals, (B) sieve, and Parsum probe (D23 inductor) for the $100 \mathrm{rpm} / 175^{\circ} \mathrm{C}$ "as made" cocrystals, (C) laser diffraction, and Parsum probe (D23 inductor) for the $100 \mathrm{rpm} /$ $175^{\circ} \mathrm{C}$ milled cocrystals.

SEM micrographs (Figure 4) of bulk IND showed irregularshaped crystals with the particle size varying from $5-10 \mu \mathrm{m}$, while the $\mathrm{SCH}$ coformer presented prismatic-shaped crystal morphology with particle sizes varying from 50 to $70 \mu \mathrm{m}$. The extruded cocrystals revealed cuboid shapes in the form of agglomerates. An increase in the screw speed and the extrusion 


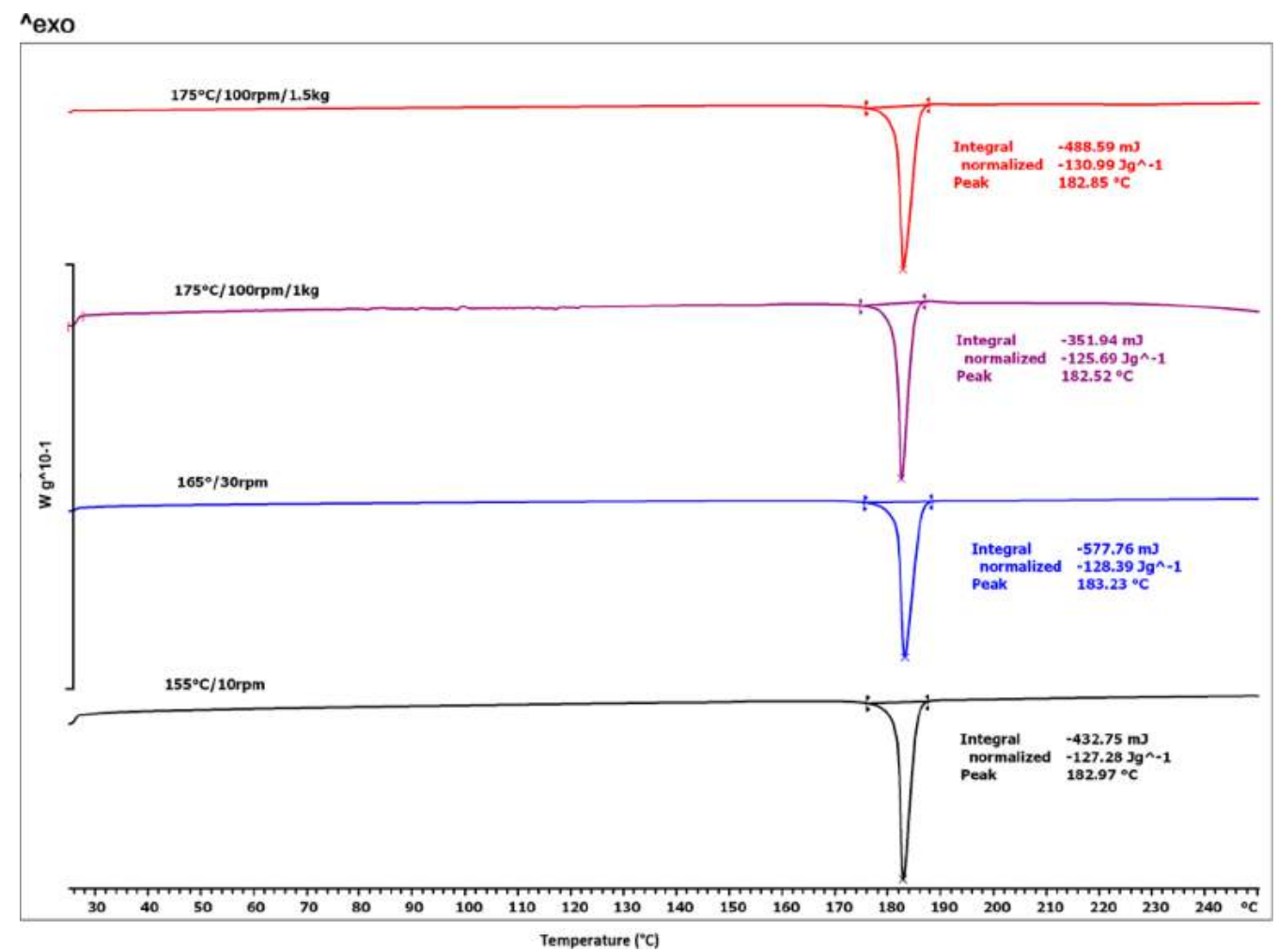

Figure 6. DSC thermograms of (black trace) $10 \mathrm{rpm} / 155^{\circ} \mathrm{C}$, (blue trace) $30 \mathrm{rpm} / 165^{\circ} \mathrm{C}$, (purple trace) $100 \mathrm{rpm} / 175^{\circ} \mathrm{C}(1.0 \mathrm{~kg} / \mathrm{h})$, and $($ red trace) $100 \mathrm{rpm} / 175^{\circ} \mathrm{C}(1.5 \mathrm{~kg} / \mathrm{h})$ extruded cocrystals.

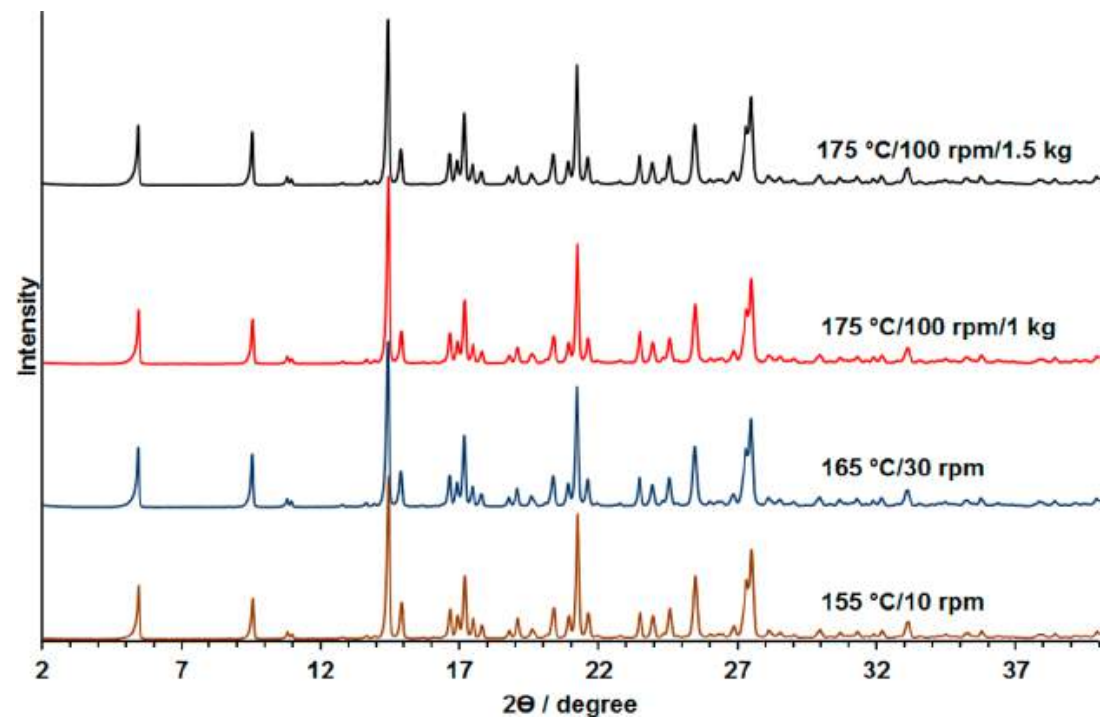

Figure 7. XRPD diffractorgrams of (brown trace) $10 \mathrm{rpm} / 155{ }^{\circ} \mathrm{C}$, (blue trace) $30 \mathrm{rpm} / 165{ }^{\circ} \mathrm{C}$, (red trace) $100 \mathrm{rpm} / 175{ }^{\circ} \mathrm{C}(1.0 \mathrm{~kg} / \mathrm{h}$ ), and (black trace) $100 \mathrm{rpm} / 175^{\circ} \mathrm{C}(1.5 \mathrm{~kg} / \mathrm{h})$ extruded cocrystals.

temperature, due to the scale-up requirements, did not have an effect on the morphology of the different cocrystal batches.

In-line particle size measurements were carried out for all the cocrystal batches during the scale-up optimization at two different stages and compared with off-line particle size analysis. The cocrystal particle size was measured at the end of the extrusion process for the "as made" batches and after milling where the size was further reduced by using a cutter mill. In order to optimize the process of in-line monitoring two parameters were selected, named D23 in-line disperser and free fall. The D23 inductor incorporates a nozzle with an air supply, which disperses and accelerates particles toward the measuring zone, while free fall applies for particles with gravitational flow. As it can be seen, both settings of the particle probe are related to the expected average particle velocity. The in-line particle size probes are placed underneath the cutter mill, and the particle size distribution is continuously recorded every $1 \mathrm{~min}$ until the end of the process.

The in-line particle size analysis revealed that IND-SCH cocrystals leave the extruder in the form of agglomerates when the extrusion temperature exceeds $165{ }^{\circ} \mathrm{C}$. The agglomerates (which constituted $\sim 30 \%$ of the total particles), produced at an 

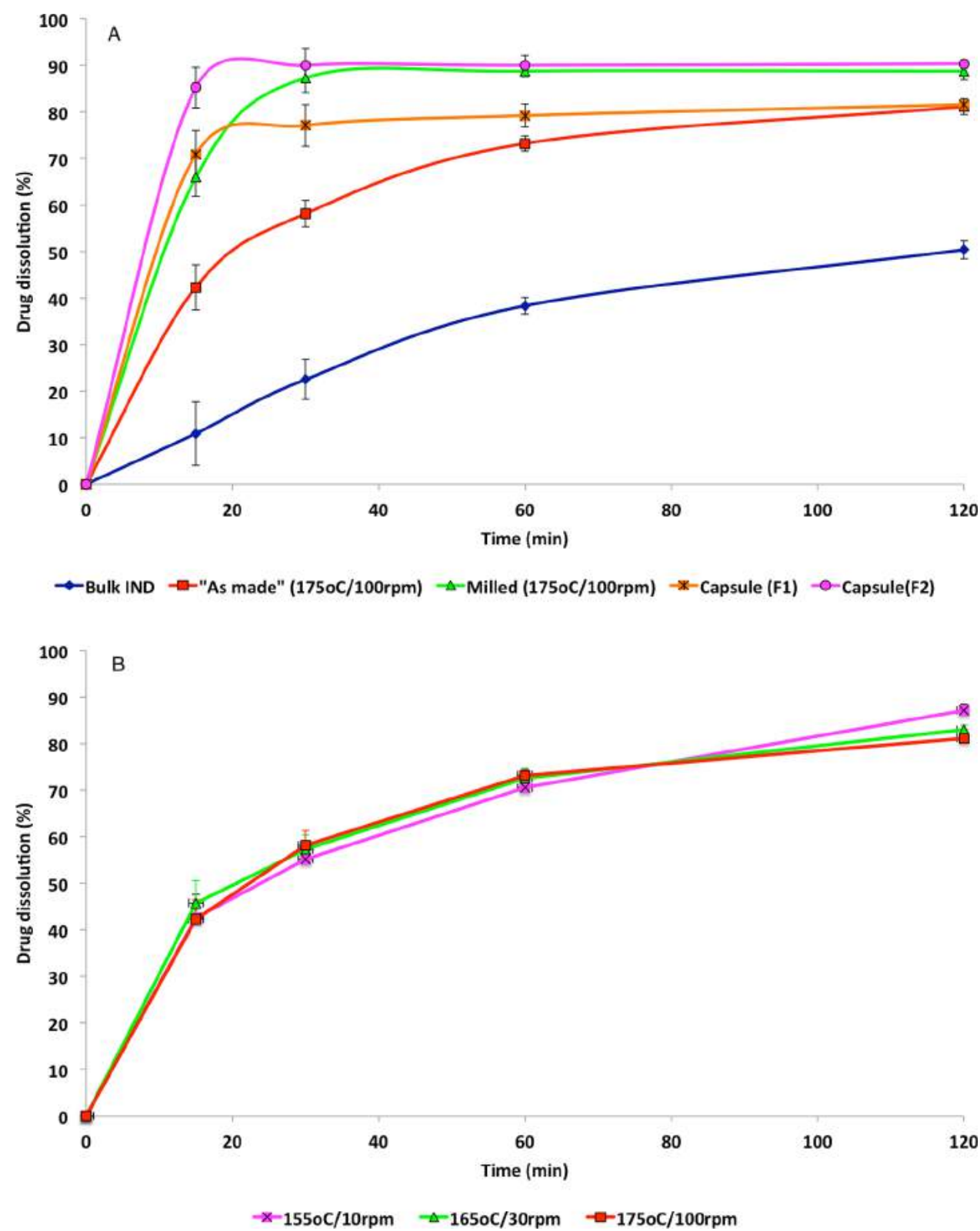

Figure 8. (a) Dissolution profiles of bulk IND, IND-SCH bulk cocrystals ("as made" and milled), and formulated in soft gelatin capsules. (b) Dissolution profiles of IND-SCH bulk cocrystals ("as made") at various extrusion processing parameters (F2, F4, F8).

extrusion temperature above $165{ }^{\circ} \mathrm{C}$, displayed a particle size between 1000 and $2000 \mu \mathrm{m}$, and thus further micronization was required before capsule filling. For this reason a cutter mill was employed at the end of the extrusion processing to reduce the particle size of the cocrystals to the desired specifications (a $250 \mu \mathrm{m}$ mesh was used). As shown in Figure 5A the free fall settings of the Parsum probe for the "as made" cocrystals displayed a similar particle size distribution in the range of 250-2000 $\mu \mathrm{m}$ with the off-line sieve analysis. However, the use of the "free fall" setting did not detect smaller particle sizes $(<250 \mu \mathrm{m})$ due to the large agglomerates obtained at the end of the extrusion process. The use of the D23 in-line disperser provided a better determination of smaller particles, but an increase in the volume (\%) particles between 1000 and $2000 \mu \mathrm{m}$ was detected. According to Silva et al. (2013), this could be due to the particle coincidence, where if, occasionally, two particles cross at the same time through the measurement cell the probe may not be able to differentiate the individual particles and regard them as a single one. ${ }^{35}$ Nevertheless, the D23 inductor showed a good correlation of the particle size distribution with sieve analysis for the "as made" cocrystals at $175{ }^{\circ} \mathrm{C} / 100 \mathrm{rpm}$ (Figure 5B).

On the basis of the foregoing results, the in-line measurements of the milled cocrystals $\left(165{ }^{\circ} \mathrm{C} / 100 \mathrm{rpm}, 175{ }^{\circ} \mathrm{C} / 100 \mathrm{rpm}\right)$ were conducted by using the D23 inductor and compared with sieve analysis and laser diffraction. The particle size distributions obtained (Figure 5C) were similar for both in-line and off-line measurements. Overall, spatial filter velocimetry proved efficient for in-line particle size monitoring and an excellent PAT tool for quality control. Tuning of the measurement parameters is a prerequisite for obtaining reliable results.

The synthesis and quality of cocrystals were further confirmed by DSC and XRPD. DSC was used to analyze extruded cocrystals in comparison to bulk materials, and Figure 6 represents the thermograms of successfully synthesized cocrystals after optimization of the process parameters. The melting endotherms appear sharp, similar to bulk IND, with melting points varying 
from 182.5 to $183.3^{\circ} \mathrm{C}$. This is impressive as the melting peaks of both small volume and scaled-up batches of cocrystals $(0.3-1.5 \mathrm{~kg} / \mathrm{h})$ lie in a very narrow temperature range suggesting a highly reproducible process. The XRPD analyses of the bulk components are shown in Figure 8 where IND showed characteristic intensity peaks at 10.25, 11.67, 16.77, 17.02, 19.68, $21.87,23.99,26.61^{\circ} 2 \theta$. Intense peaks of bulk SCH were identified at $9.56,15.91,16.02,17.23,19.13,25.142 \theta$. The diffractogram of the IND-SCH physical mixture presented XRPD peaks of lower intensities that belonged to both IND and SCH.

However, the diffractograms of the extruded cocrystals showed a unique XRPD pattern compared to their parent compounds, which were identical to published data collected from the Cambridge Crystallographic Data Centre (CCDS) (CCDS REF: UFERED). All the unsuccessfully extruded cocrystals presented the same XRPD patterns with two peaks at $10.21^{\circ}$ and $14.42^{\circ} 2 \theta$, respectively (Figure $2 S$ ). These are characteristic peaks for IND and suggest the presence of unreacted drug due to incomplete cocrystal formation. High purity cocrystals were obtained with optimized process variables (Table 1) without any traces of unreacted material, and typical peaks of IND-SCH cocrystals were identified at $2 \theta$ values of $5.43,10.89,14.42,21.22$, 25.45 , and $27.07^{\circ}$. The Rietveld analysis showed that the purity of extruded cocrystal batches varied from $98.4-98.9 \%$ including the scaled - up extrudates.

The dissolution rates of synthesized cocrystals were investigated in phosphate buffer solution $(\mathrm{pH}$ 6.8) in comparison to bulk IND. The data in Figure 8a show a significant increase in the dissolution rates of the cocrystals with $60-70 \%$ being dissolved within the first $60 \mathrm{~min}$ with respect to $30 \%$ of the bulk drug. ${ }^{32}$ A Kruskal-Wallis nonparametric analysis showed no significant difference of the dissolution rates for cocrystals formed at various temperatures $\left(155-175{ }^{\circ} \mathrm{C}\right)$ during the process scale-up. As shown in Figure $8 \mathrm{~b}$ the $\mathrm{CBZ}-\mathrm{SCH}$ dissolution rates were almost identical with $81-87 \%$ dissolved in $120 \mathrm{~min}$. This is an important observation showing that temperature has no impact on the dissolution rates of the cocrystals. It is obvious that processing parameters such as feed rate and screw speed do not influence the dissolution behavior of the cocrystals either. However, it worth mentioning that this observation is effective only for the successful scaled-up cocrystals batches, which present the similar crystallinity, estimated by Rietveld analysis. In a previous study, Moradiya ${ }^{36,37}$ et al. showed that extrusion temperatures affect the quality of cocrystals and subsequently the dissolution rates. In contrast, the particle size of cocrystals can have an influence on their dissolution profiles. ${ }^{38}$ As shown in Figure 8a cocrystals subjected to processing by milling produced smaller particles with increased amounts of fine particles between 63 and $125 \mu \mathrm{m}$. As a result the dissolution rate of cocrystals increased to $60 \%$ within the first $15 \mathrm{~min}$ and $70 \%$ in $30 \mathrm{~min}$. Figure $8 \mathrm{a}$ also shows the effect of the soft gelatin capsules and the bulk excipients on the rates of dissolution of the cocrystals. The filling of gelatin capsules with cocrystals resulted in $20 \%$ less drug release in the first $10 \mathrm{~min}$. The results showed that careful consideration of the selected capsule fillers is required as they also caused retardation of IND release compared to capsules filled with pure cocrystals.

\section{CONCLUSIONS}

In conclusion the current study is a paradigm that continuous manufacturing of pharmaceutical cocrystals with high throughput, yield, and quality can be successfully achieved by using extrusion processing coupled with PAT tools and downstream processing equipment. CM was developed by using only six operational units with small footprint for the production of cocrystals filled in capsules. The implementation of a $\mathrm{QbD}$ approach led to process optimization and helped to identify the process boundary.

\section{ASSOCIATED CONTENT}

\section{S Supporting Information}

The Supporting Information is available free of charge on the ACS Publications website at DOI: 10.1021/acs.cgd.6b00402.

(a) Images of the extruder, cutter mill, capsule filler and particle size probe; (b) second derivative NIR spectra of bulk IND, SCH, and their physical mixture; (c) second derivative of unsuccessful cocrystals batches; (d) DSC thermograms of bulk IND, SCH, and their physical mixture; (e) DSC thermograms of unsuccessful cocrystals batches; (f) XRPD diffractograms of unsuccessful cocrystals batches (PDF)

\section{AUTHOR INFORMATION}

\section{Corresponding Author}

*Tel.: +44(0)2083318440. Fax:+44(0)2083319805. E-mail: D.Douroumis@gre.ac.uk.

\section{Notes}

The authors declare no competing financial interest.

\section{REFERENCES}

(1) Baumgartner, R.; Eitzlmayr, A.; Matsko, N.; Tetyczka, C.; Khinast, J.; Roblegg, E. Int. J. Pharm. 2014, 477, 1-11.

(2) Rogers, A.; Ierapetritou, M. Comput.-Aided Chem. Eng. 2015, 37, $85-92$.

(3) Thérèse, S.; Mortier, F. C.; Gernaey, K. V.; De Beer, T.; Nopens, I. Eur. J. Pharm. Biopharm. 2014, 86, 532-543.

(4) Sundaramoorthy, A.; Li, X.; Evans, J. M. B.; Barton, P. I. Comput.Aided Chem. Eng. 2012, 31, 1135-1139.

(5) Singh, R.; Ierapetritou, M.; Ramachandran, R. Int. J. Pharm. 2012, 438, 307-326.

(6) Kumar, A.; Gernaey, K. V.; De Beer, T.; Nopens, I. Comput.-Aided Chem. Eng. 2015, 37, 2165-2170.

(7) Ley, S. V.; Fitzpatrick, D. E.; Ingham, R. J.; Myers, R. M. Angew. Chem., Int. Ed. 2015, 54, 3449-64.

(8) Mascia, S.; Heider, P. L.; Zhang, H.; Lakerveld, R.; Benyahia, B.; Barton, P. I.; Braatz, R. D.; Cooney, C. L.; Evans, J. M. B.; Jamison, T. F.; Jensen, K. F.; Myerson, A. S.; Trout, B. L. Angew. Chem., Int. Ed. 2013, $52,12359-12363$.

(9) Snead, D. R.; Jamison, T. F. Angew. Chem., Int. Ed. 2015, 54, $983-$ 987.

(10) Goyal, S.; Thorson, M. S.; Zhang, G. G. Z.; Gong, Y.; Kenis, P. J. A. Cryst. Growth Des. 2012, 12, 6023-6034.

(11) Sugandha, K.; Kaity, S.; Mukherjee, S.; Isaac, J.; Ghosh, A. Cryst. Growth Des. 2014, 14, 4475-4486.

(12) Eddleston, M. D.; Patel, B.; Day, G. M.; Jones, W. Cryst. Growth Des. 2013, 13, 4599-4606.

(13) Leung, D. H.; Lohani, S.; Ball, R. G.; Canfield, N.; Wang, Y.; Rhodes, T.; Bak, A. Cryst. Growth Des. 2012, 12, 1254-1262.

(14) Maddileti, D.; Swapna, B.; Nangia, A. Cryst. Growth Des. 2014, 14, 2557-2570.

(15) Daurio, D.; Medina, C.; Saw, R.; Nagapudi, K.; Alvarez-Núñez, F. Pharmaceutics 2011, 3, 582-600.

(16) Jayasankar, A.; Somwangthanaroj, A.; Shao, Z.; RodríguezHornedo, N. Pharm. Res. 2006, 23, 2381-2392.

(17) Grobelny, P.; Mukherjee, A.; Desiraju, G. CrystEngComm 2011, $13,4358-4364$.

(18) Liu, X.; Lu, M.; Guo, Z.; Huang, L.; Feng, X.; Wu, C. Pharm. Res. 2012, 29, 806-817.

(19) Childs, S.; Wood, P.; Rodríguez-Hornedo, N.; Reddy, L.; Hardcastle, K. Cryst. Growth Des. 2009, 9, 1869-1888. 
(20) Boksa, K.; Otte, A.; Pinal, R. J. Pharm. Sci. 2014, 103, 2904-2910.

(21) Muzzio, F. J. A. AICHE 2003 Annual Meeting, San Francisco, CA; http://www.aiche.org/conferences/techprogram/paperdetail. asp?PaperID $=2036 \& D S N=$ annual03.

(22) Dhumal, R.; Kelly, A.; York, P.; Coates, P.; Paradkar, A. Pharm. Res. 2010, 27, 2725-2733.

(23) Mohammad, M. A.; Alhalaweh, A.; Velaga, S. P. Hansen solubility parameter as a tool to predict cocrystal formation. Int. J. Pharm. 2011, $407,63-71$.

(24) Almeida, A.; Claeys, B.; Remon, J. P.; Vervaet, C. In Hot-Melt Extrusion: Pharmaceutical Applications; Douroumis, D., Ed.; John Wiley \& Sons Ltd: UK, 2012; pp 43-69.

(25) Dreiblatt, A. In Hot-Melt Extrusion: Pharmaceutical Applications; Douroumis, D., Ed.; John Wiley \& Sons Ltd: UK, 2012; pp 254-266.

(26) Singh, B.; Rizvi, S. S. H. J. Food Process Eng. 1998, 21, 111-126.

(27) Prat, L.; Guiraud, P.; Rigal, L.; Gourdon, C. Chem. Eng. Process. 1999, 38, 73-83.

(28) Ziegler, G. R.; Carlos, A.; Aguilar, C. A. J. Food Eng. 2003, 59, $161-167$.

(29) Nauman, E. B. In Scale-Up of Chemical Processes; Bisio, A.; Kabel, R. L., Eds.; John Wiley \& Sons: New York, 1985; pp 275-308.

(30) Portillo, P. M.; Ierapetritou, M. G.; Muzzio, F. J. Powder Technol. 2008, 182, 368-378.

(31) Alleso, M.; Velaga, S.; Alhalaweh, A.; Cornett, C.; Rasmussen, M. A.; van den Berg, F.; Lopez de Diego, H.; Rantanen, J. Anal. Chem. 2008, $80,7755-7764$.

(32) Basavoju, S.; Bostrom, D.; Velaga, S. P. Pharm. Res. 2008, 25, $530-41$.

(33) Zhang, G. C.; Lin, H. L.; Lin, S. Y. J. Pharm. Biomed. Anal. 2012, $66,162-169$.

(34) Islam, M. T.; Scoutaris, N.; Maniruzzaman, M.; Moradiya, H. G.; Halsey, S. A.; Bradley, M. S. A.; Chowdhry, B. Z.; Snowden, M. J.; Douroumis, D. Eur. J. Pharm. Biopharm. 2015, 96, 106-116.

(35) Silva, A. F.; Burggraeve, A.; Denon, Q.; Van der Meeren, P.; Sandler, N.; Van Den Kerkhof, T.; Hellings, M.; Vervaet, C.; Remon, J. P.; Lopes, J. A.; De Beer, T. Eur. J. Pharm. Biopharm. 2013, 85, 1006-18.

(36) Moradiya, H.; Islam, M. T.; Halsey, S. A.; Maniruzzaman, M.; Chowdhry, B. Z.; Snowden, M. J.; Douroumis, D. CrystEngComm 2014, $16,3573-83$.

(37) Moradiya, H.; Islam, M. T.; Woollam, G.; Slipper, I. J.; Halsey, S. A.; Snowden, M. J.; Douroumis, D. Cryst. Growth Des. 2014, 14, 189198.

(38) Shiraki, K.; Takata, N.; Takano, R.; Hayashi, Y.; Terada, K. Pharm. Res. 2008, 25, 2581-92. 


\section{Supporting Information}

\section{Continuous Manufacturing of High Quality Pharmaceutical Cocrystals Integrated with Process Analytical Tools for In-Line Process Control}

Hiren G. Moradiya ${ }^{1}$, Muhammad T. Islam ${ }^{1}$, Nicolaos Scoutaris ${ }^{1}$, Sheelagh A. Halsey$^{2}$, Babur Z. Chowdhry ${ }^{1}$, Dennis Douroumis ${ }^{1}$

${ }^{1}$ Faculty of Engineering and Science, University of Greenwich, Medway Campus, Chatham Maritime, Kent ME4 4TB, UK

${ }^{2}$ ThermoFisher Scientific, Stafford House, Boundary Way, Hemel Hempstead HP2 7GE, UK

\footnotetext{
${ }^{1}$ Corresponding author, Department of Pharmaceutical, Chemical \& Environmental Sciences, Faculty of Engineering and Science, University of Greenwich, Medway Campus, Chatham Maritime, Kent ME4 4TB, UK. Tel.: +44 (0) 208331 8440; Fax: +44 (0) 2083319805.

E-mail address: D.Douroumis@gre.ac.uk (D. Douroumis).
} 


\section{Additional Figures}

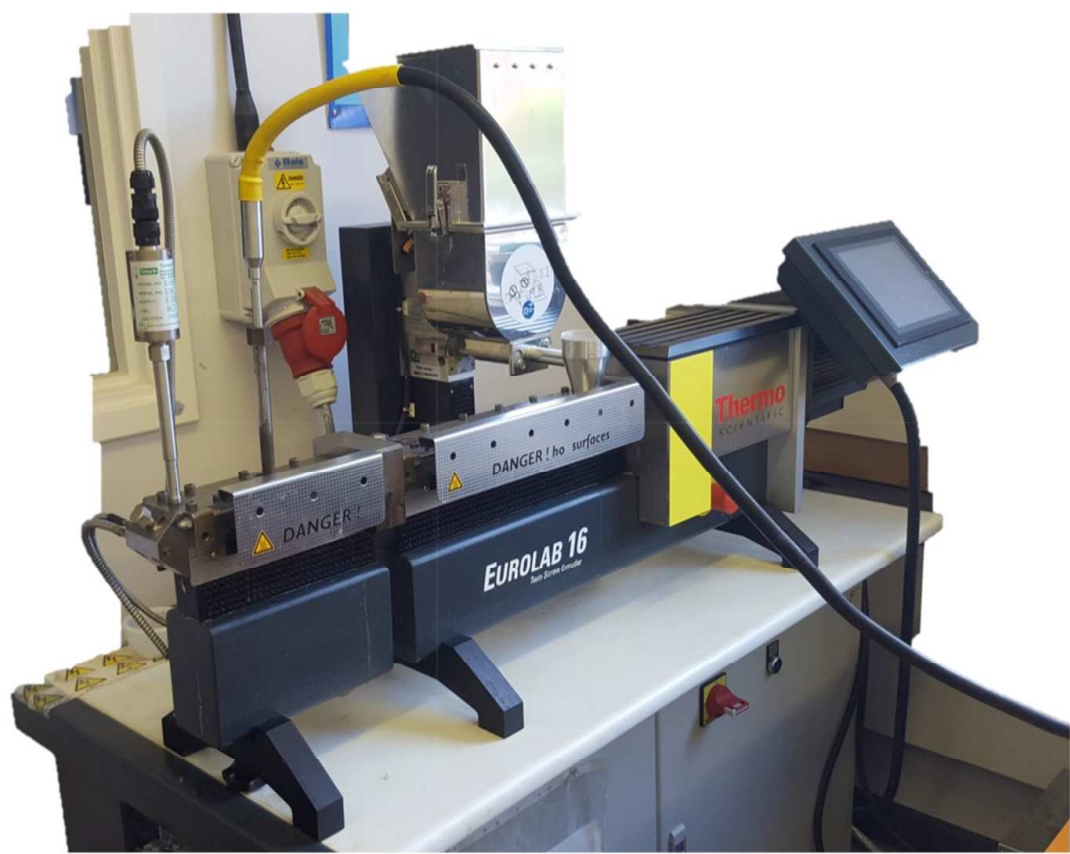

Figure S1. Image of a twin - screw Eurolab 16 extruder use for continuous cocrystallization processing.

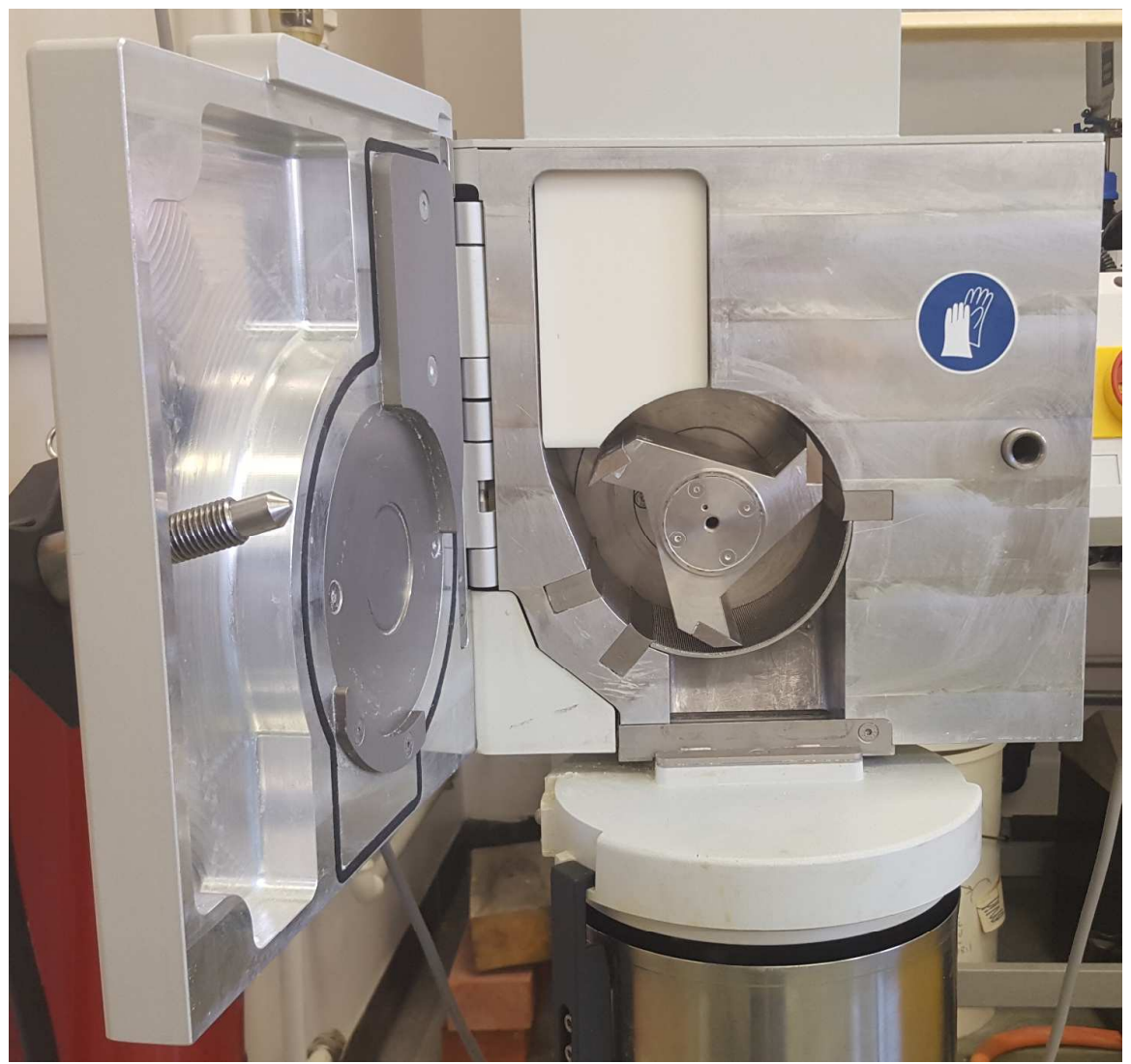

Figure S2. Image of the cutter mill used for cocrystal particle size reduction. 


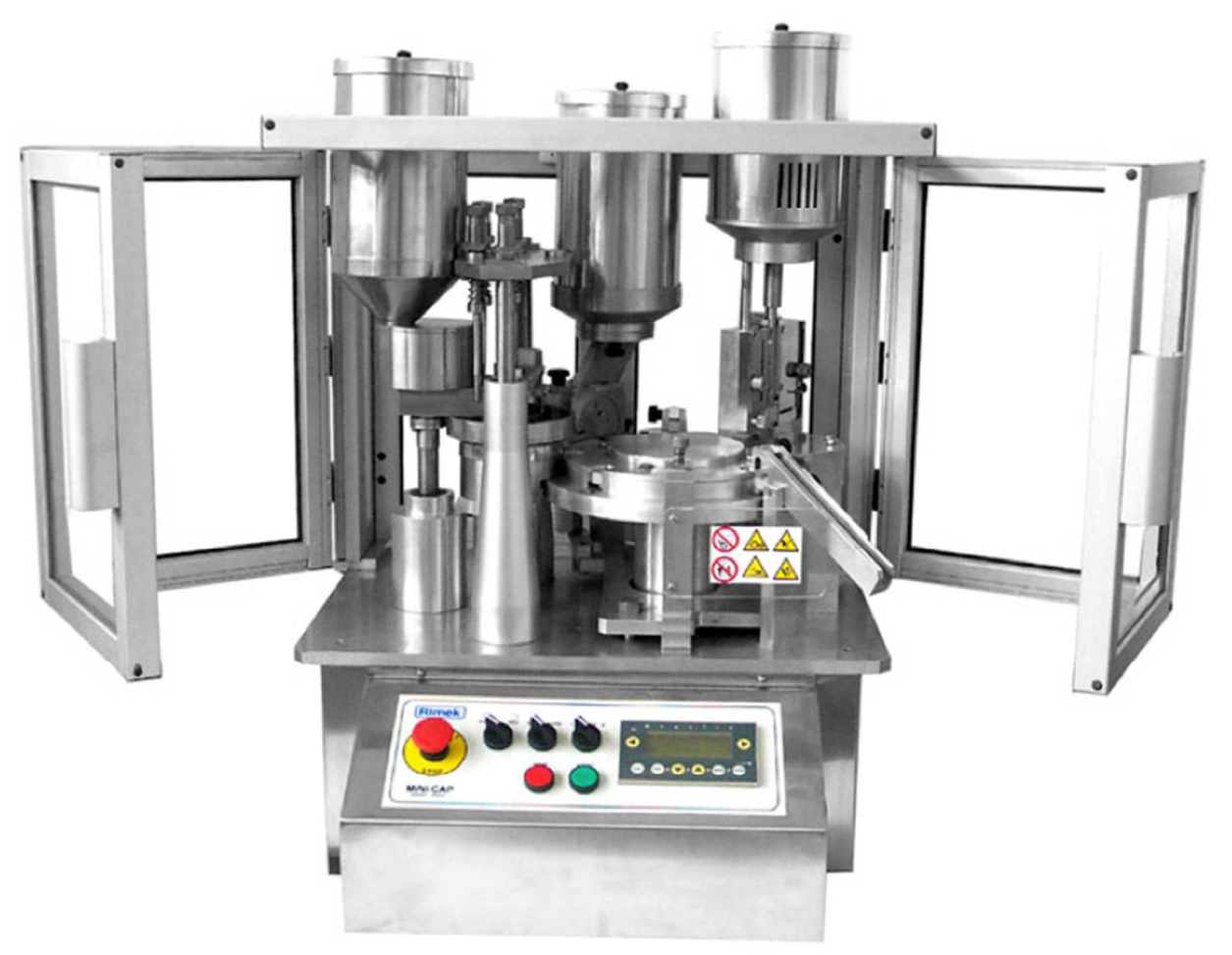

Figure S3. Image of the Mini Cap capsule filler.

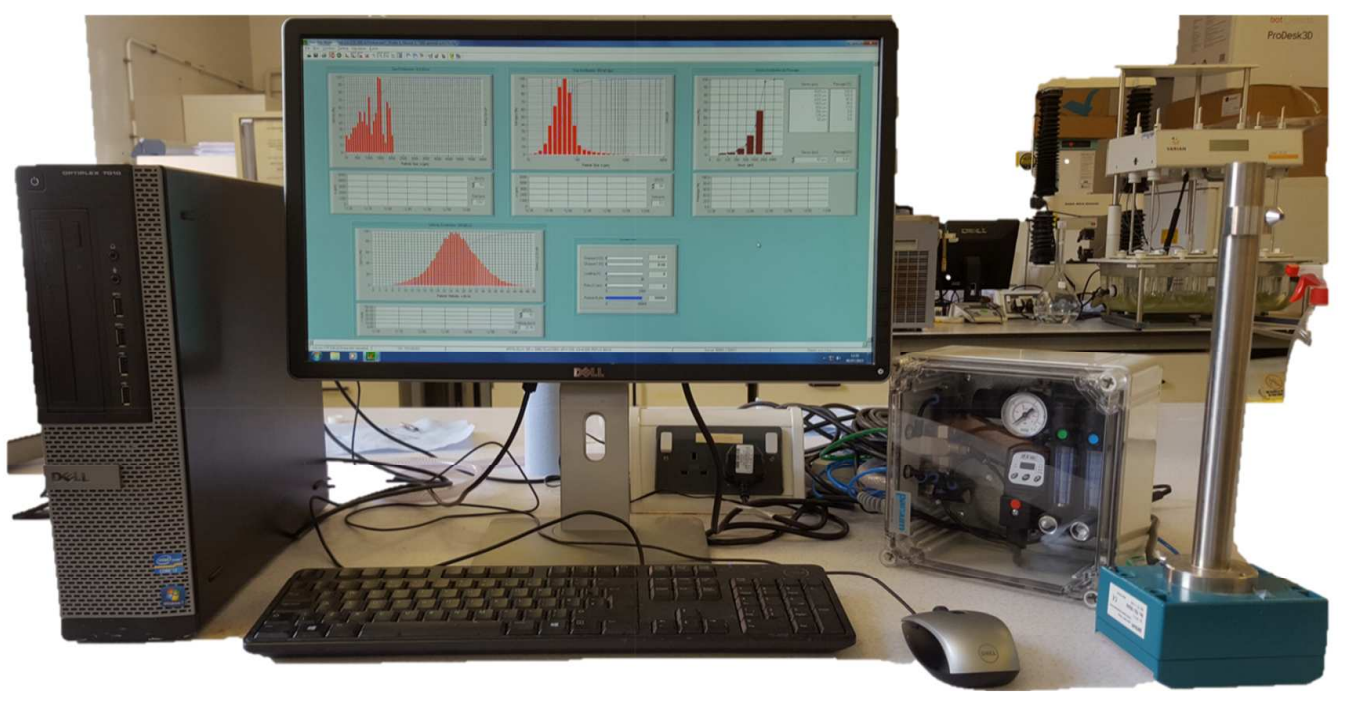

Figure S4. Image of the Parsum probe used for in line particle size measurements. 


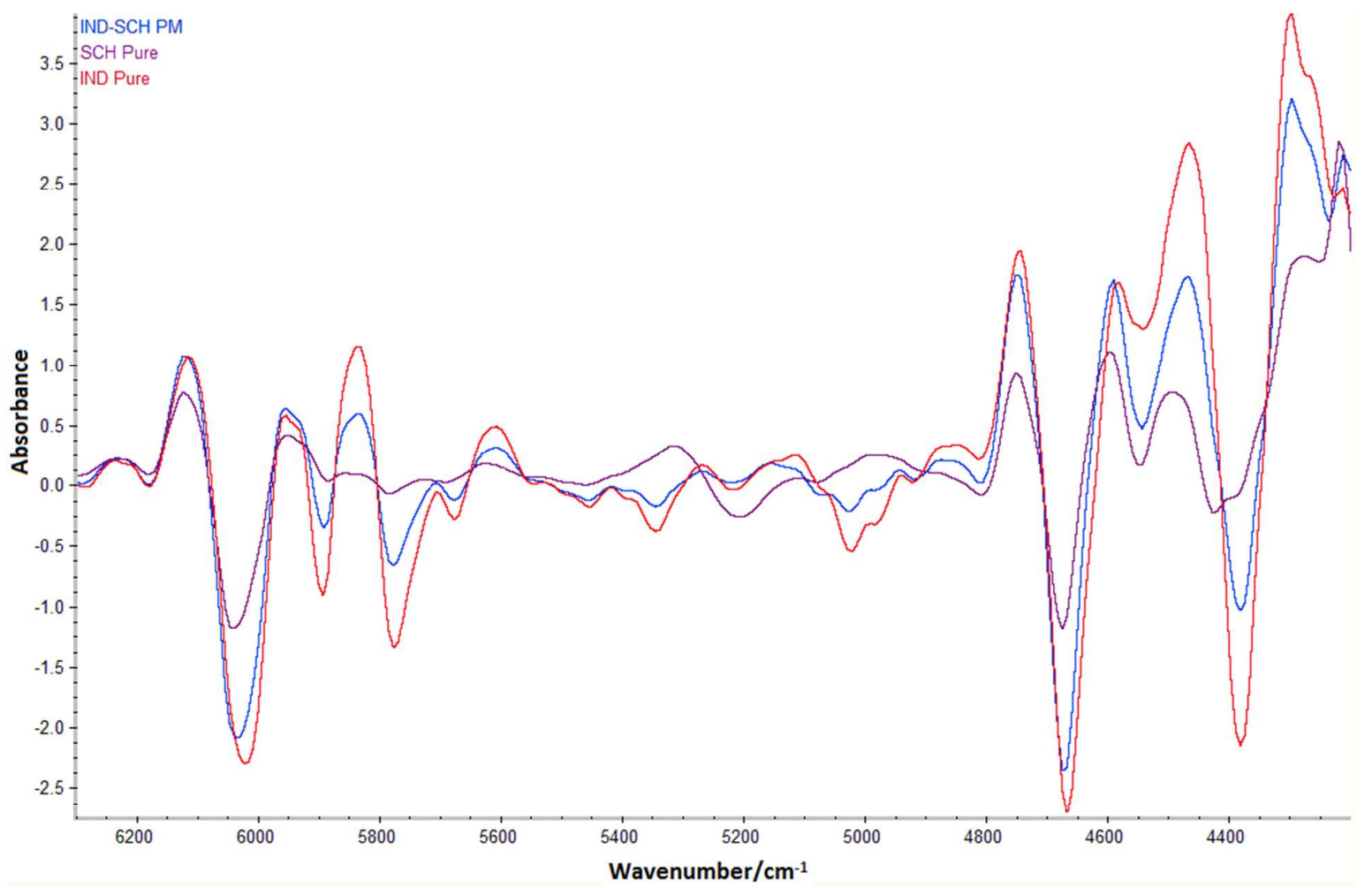

Figure S5. $2^{\text {nd }}$ derivative NIR spectra of bulk IND, SCH and their physical mixture.

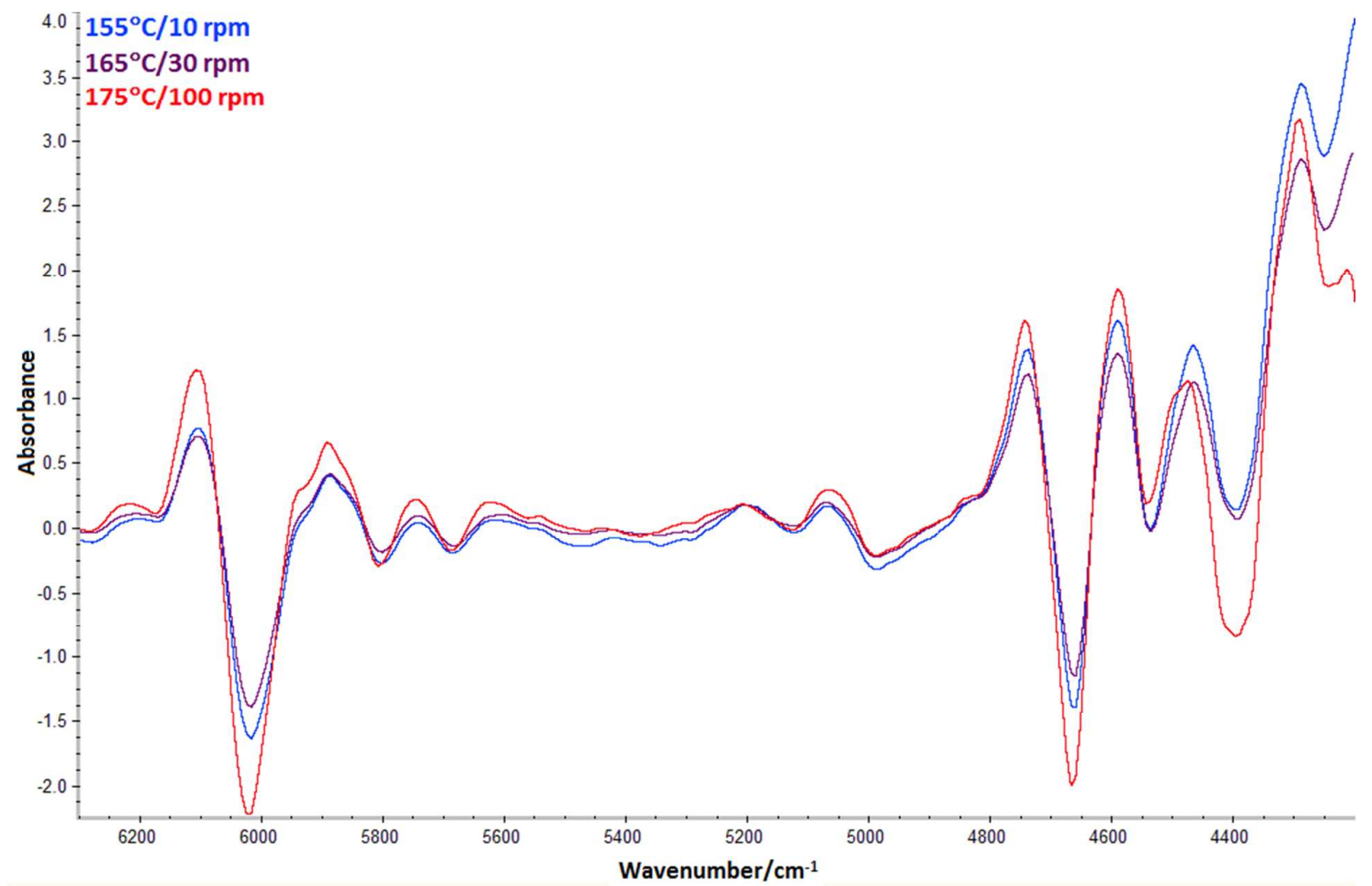

Figure 6S. $2^{\text {nd }}$ derivative NIR spectra of unsuccessfully processed cocrystals (F1, F3, F5). 


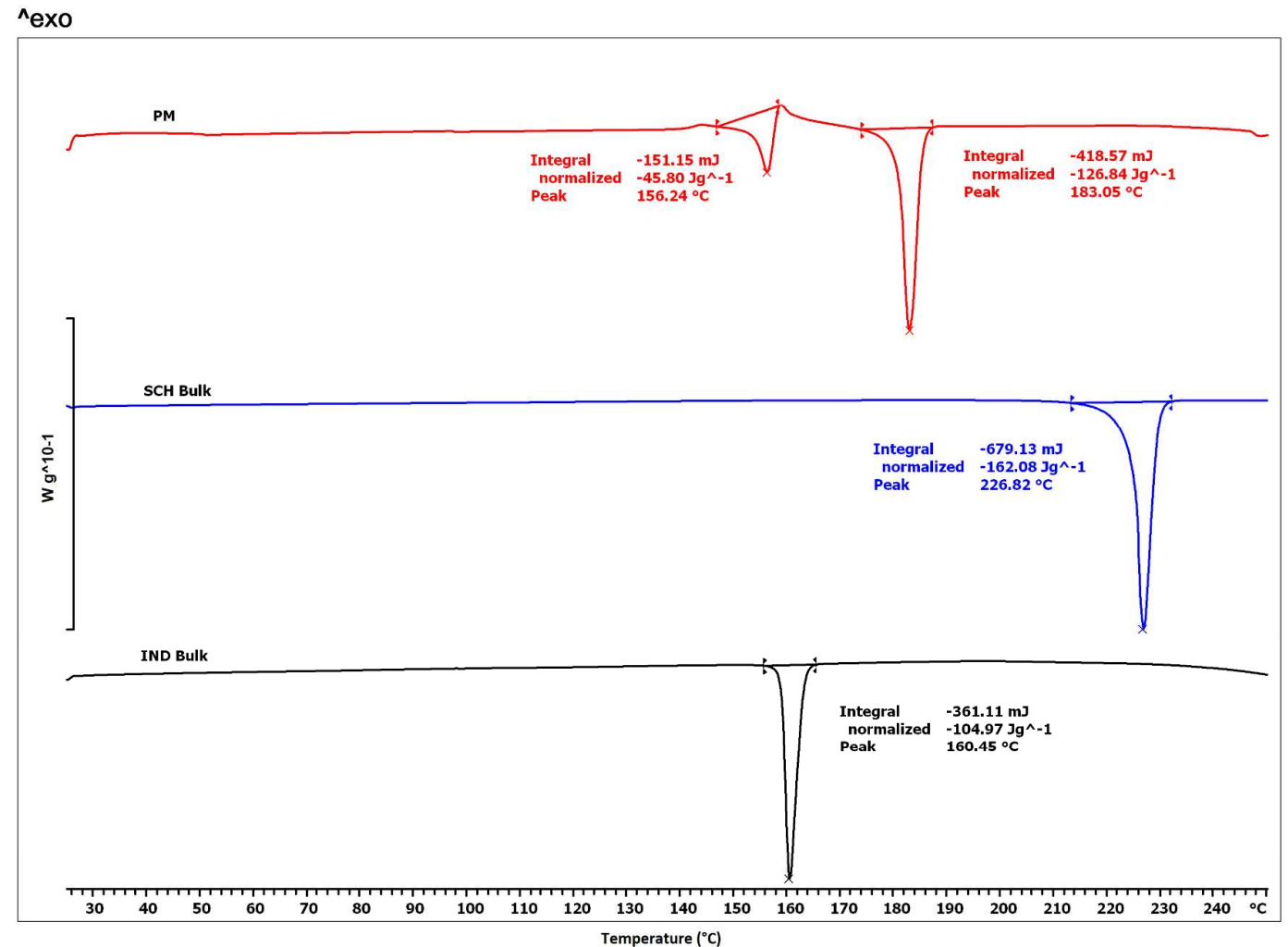

Figure 7S. DSC thermograms of bulk IND, SCH and their physical mixture.

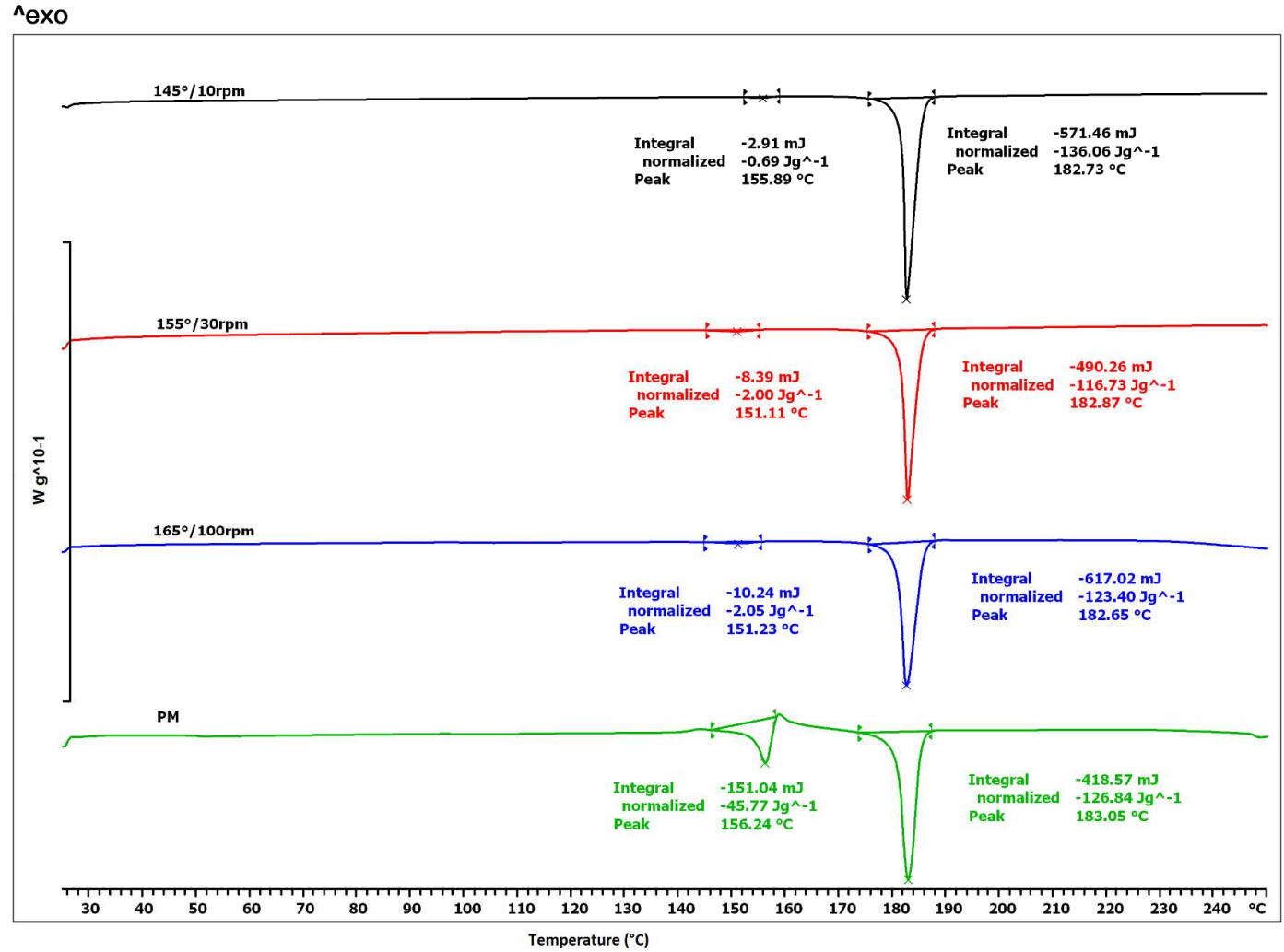

Figure S8. DSC thermograms of unsuccessfully processed cocrystals (F1, F3, F5) and their physical mixture. 


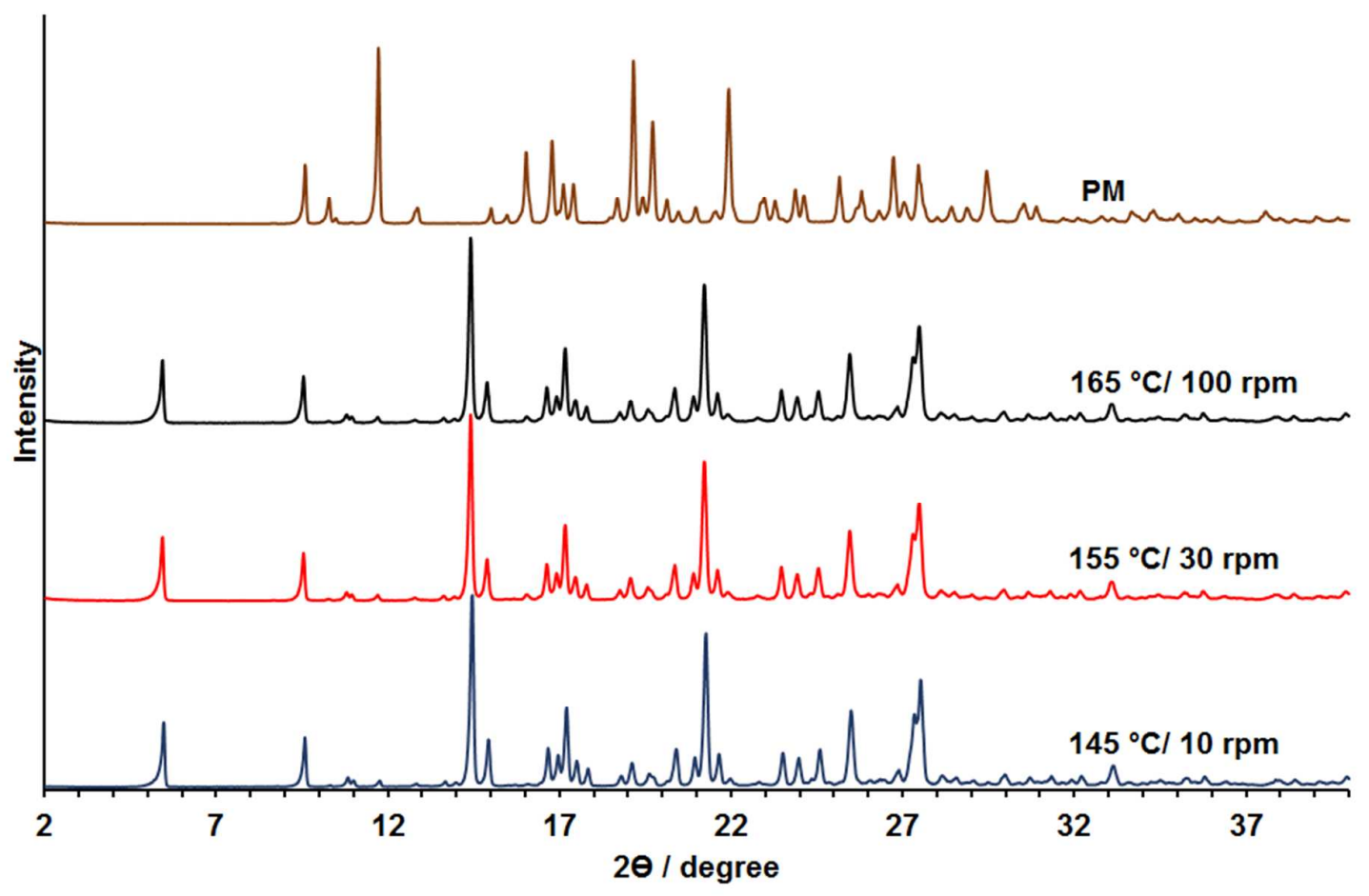

Figure S9. XRPD diffractograms of unsuccessfully processed cocrystals (F1, F3, F5) and their physical mixture. 